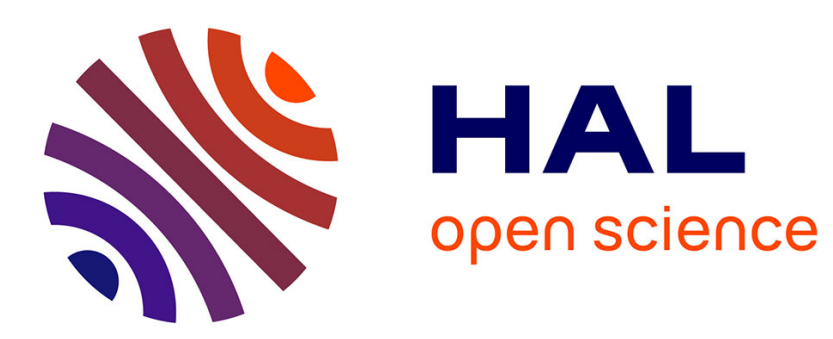

\title{
Substorm expansion phase: Observations from Geotail, Polar and IMAGE network
}

Sylvaine Perraut, Olivier Le Contel, Alain Roux, Georges Parks, D. Chua, M. Hoshino, T. Mukai, T. Nagai

\section{- To cite this version:}

Sylvaine Perraut, Olivier Le Contel, Alain Roux, Georges Parks, D. Chua, et al.. Substorm expansion phase: Observations from Geotail, Polar and IMAGE network. Journal of Geophysical Research Space Physics, 2003, 108 (A4), 10.1029/2002JA009376 . hal-02550761

\section{HAL Id: hal-02550761 https://hal.science/hal-02550761}

Submitted on 28 Jan 2021

HAL is a multi-disciplinary open access archive for the deposit and dissemination of scientific research documents, whether they are published or not. The documents may come from teaching and research institutions in France or abroad, or from public or private research centers.
L'archive ouverte pluridisciplinaire HAL, est destinée au dépôt et à la diffusion de documents scientifiques de niveau recherche, publiés ou non, émanant des établissements d'enseignement et de recherche français ou étrangers, des laboratoires publics ou privés. 


\title{
Substorm expansion phase: Observations from Geotail, Polar and IMAGE network
}

\author{
Sylvaine Perraut, ${ }^{1}$ Olivier Le Contel, ${ }^{1}$ Alain Roux, ${ }^{1}$ G. Parks, ${ }^{2}$ D. Chua,${ }^{2}$ M. Hoshino, ${ }^{3}$ \\ T. Mukai, ${ }^{4}$ and T. Nagai ${ }^{5}$ \\ Received 12 March 2002; revised 4 November 2002; accepted 12 February 2003; published 22 April 2003.
}

[1] We describe the signature of a substorm detected in the midtail while Geotail was located close to the midnight meridian. At the same time, the UVI imager on board Polar identifies a bulge which develops at low latitude and rapidly expands towards the north, east, and west, corresponding to the expansion phase. The magnetograms of the IMAGE network are consistent with these observations; during the expansion phase they give evidence for a northward expansion of the magnetic perturbation. Mapping indicates that the Geotail footprint is located north of the initial bulge and south of the high-latitude oval. During the expansion phase, Geotail is located in the center of the neutral sheet and detects an ion flow velocity, perpendicular to Bo and directed tailward while Bz changes from positive to negative. During the recovery phase, Geotail, which is not at the center of the sheet anymore, detects an ion velocity directed earthward but essentially field aligned, while $\mathrm{Bz}$ is positive and the high-latitude auroral structure is located north of Geotail footprint. The radial component of the velocity is always dominant. We interpret these observations as evidence for a tailward moving dipolarization front that first destroys the inner part of the thin current sheet (TCS) formed during the growth phase. This dipolarization/current disruption starts in the near-Earth plasma sheet and expands tailward. This "erosion" produces a negative $\mathrm{Bz}$ component at the earthward edge of the TCS. For large enough distances this contribution can eventually be dominant, thereby producing a negative $\mathrm{Bz}$. In this interpretation the formation of an X-point/X-line is the consequence of the erosion of the currents in near-Earth tail. Present observations give evidence for an association between increases in the ion velocity and small-scale Alfvenic fluctuations. The plasma sheet electrons are heated via interaction with the waves. This heating is preferentially along the direction of the magnetic field. Large ion flow velocities coincide with wave observations. INDEX TERMS: 2740 Magnetospheric Physics: Magnetospheric configuration and dynamics; 2764 Magnetospheric Physics: Plasma sheet; 2704 Magnetospheric Physics: Auroral phenomena (2407); 2788 Magnetospheric Physics: Storms and substorms; KEYWORDS: substorm, aurora, dipolarization, disruption, magnetotail

Citation: Perraut, S., O. Le Contel, A. Roux, G. Parks, D. Chua, M. Hoshino, T. Mukai, and T. Nagai, Substorm expansion phase: Observations from Geotail, Polar and IMAGE network, J. Geophys. Res., 108(A4), 1159, doi:10.1029/2002JA009376, 2003.

\section{Introduction}

[2] The interaction between the solar wind and the Earth's magnetic field leads to the formation of a large reservoir of hot plasma, the plasma sheet. The dynamics of the plasma sheet is governed by a fundamental process: magnetospheric

\footnotetext{
${ }^{1}$ Centre d'Etude des Environnements Terrestre et Planétaires/Centre National de la Recherche Scientifique/Université de Versailles-Saint Quentin, Vélizy, France.

${ }^{2}$ Department of Earth and Space Sciences, University of Washington, Seattle, Washington, USA.

${ }^{3}$ University of Tokyo, Tokyo, Japan.

${ }^{4}$ Institute of Space and Aeronautical Science, Sagamihara, Kanagawa, Japan.

${ }^{5}$ Tokyo Institute of Technology, Tokyo, Japan.
}

Copyright 2003 by the American Geophysical Union. 0148-0227/03/2002JA009376 substorms which correspond to the rapid release of the magnetic energy stored in the magnetotail. A substorm involves the systematic occurrence of physical processes that have distinctive signatures in the deep tail as well as in the ionosphere. Thus the energy transfer from the solar wind to the magnetosphere-ionosphere system involves a series of related mechanisms. The question is to understand this chain of processes. Here we concentrate our attention on the transport of the plasma in the Central Plasma Sheet (CPS) and Plasma Sheet Boundary Layer (PSBL) and on the relation between this transport and the presence of waves at frequencies around the proton gyrofrequency.

[3] Bursty high-speed ( $>400 \mathrm{~km} / \mathrm{s})$ plasma flows, termed bursty bulk flow (BBFs) lasting short times, typically a few minutes, have been extensively studied [e.g., Baumjohann et al., 1990; Angelopoulos et al., 1994]. Statistically, the direction of the flow which has a strong radial component 
depends on the distance in the tail: for $X_{G S M}>-25 R_{E}$ the flow is generally directed earthward. Beyond $25 R_{E}$ the flows are usually directed tailward [Nagai et al., 1998a]. Statistics show that the ion flow velocity decreases as the distance from the Earth decreases, which was interpreted as evidence for flow braking [Shiokawa et al., 1997]. The flow velocity varies like $\mathrm{E} / \mathrm{B}$; thus this statistical result is strongly influenced by the radial variation of the magnetic field. The selection criterion used by Baumjohann et al. [1990] did not take the magnetic field variation into account. As a matter of fact, more recent statistics [Schödel et al., 2001] show that the flux transport depends little on the radial distance. In other words, the westward electric field depends little on the distance and the decrease of the flow velocity simply comes from the variation of the magnetic field at the equator, with the radial distance. Angelopoulos et al. [1994] also showed that high transport rates (energy, magnetic flux) are attained in BBFs and suggested that BBFs could take care of a large fraction of the earthward transport. This conclusion was challenged by Paterson et al. [1998, 1999] who pointed out that large flows are connected with substorm activation and concluded that BBFs do not contribute significantly to the transport in the near-Earth plasma sheet, at least during quiet times. As these studies concern mainly distances beyond $10 R_{E}$, the midnight region close to the Earth $\left(6-10 R_{E}\right)$ is not covered. A study of Le Contel et al. [2001b], based on GEOS data, showed flows with a smaller velocity (typically $100 \mathrm{~km} / \mathrm{s}$ ) but comparable electric fields. The ion flows are directed alternately towards the Earth and towards the tail.

[4] Wave activation is often observed at substorms. At the geostationary orbit, small-scale Alfvénic fluctuations are systematically observed at substorm onset and during the expansion phase [Perraut et al., 2000b]. As shown by Le Contel et al. [2001b], plasma transport can be controlled by the amplitude of these waves. Following the kinetic approach developed by Le Contel et al. [2000] for magnetospheric substorm, the following scenario has been proposed: During the growth phase, the response of the plasma to an externally applied electromagnetic perturbation implies (via the quasi-neutrality equation) the development of an electrostatic potential, constant along a given magnetic field line, and of a parallel current. The electrostatic part of the electric field tends to quench the induced part, which prevents fast transport from occurring. As soon as a large parallel current develops, however, Current Driven Alfvén (CDA) waves develop. CDA waves cancel the electrostatic field via electron diffusion, thereby enabling fast transport. The present paper aims at investigating the possible existence of the same mechanism further out in the tail.

[5] Low-frequency electromagnetic waves have also been observed on board AMPTE/IRM satellite at distances between 9 and $19 R_{E}$. Indeed, Bauer et al. [1995] found that the highest values of their intensity were connected with high-speed flows and strong changes in density and temperature in CPS. Strong electromagnetic fluctuations at a distance around $18 R_{E}$ have also been detected in the PSBL [Angelopoulos et al., 1989]. Angelopoulos et al. [1989] have shown that the plasma distribution functions detected by ISEE are potential sources of free energy, in particular, for the kink-like instability driven by a fieldaligned current. However, they did not consider the role of this instability on the electron diffusion via their parallel electric field component. Using Geotail data, Shinohara et al. [1998] and Sigsbee et al. [2001] have identified electromagnetic wave activity in the lower hybrid frequency range at and near the neutral sheet, near the substorm onset site close to $15 R_{E}$. Hoshino et al. [1994] also used Geotail data to give evidence for fluctuations at frequencies of the order of the proton gyrofrequency.

[6] In this work we study two events detected while Geotail was located around $20 R_{E}$. From a fixed position, Geotail detects a tailward flow followed by an earthward flow. These observations are interpreted with the help of ground data registered in the vicinity of the Geotail footprint and Polar images taken at the same time. Polar gives a global image of the auroral activity as a function of time. From the comparison between ionospheric and magnetospheric observations, we try to draw some conclusions on the relation between flow directions measured on board Geotail, the dipolarization/current disruption, and the wave activity. In order to substantiate the scenario described above, we have computed the magnetic variations induced by the presence of a current sheet in the tail. We also show the time variation of electromagnetic fluctuations at frequencies around the proton gyrofrequency and investigate their relation with particle distribution functions measured simultaneously on board Geotail.

[7] The first section deals with low-altitude observations from the ground and Polar. The second section aims at establishing the relationship between the flow velocity measured in the tail (with Geotail) and the location of the auroral structures observed by Polar. The magnetic variations induced by a tail current sheet are discussed in the third section. A simple model is proposed to help interpreting Geotail observations. A detailed analysis of the substorm expansion phase and of the role of current driven Alfvén waves is developed in the last section.

\section{Low-Altitude Observations}

[8] Two different events have been selected for this case study. 15 December 1996 is particularly interesting for a comparison between ground-based measurements and Geotail observations, since the footprint of Geotail is in the vicinity of the IMAGE network. A complete view of the auroral activity is obtained from the UV images provided by Polar. Per contra, during this event, Geotail was not located at a suitable position with respect to the satellite receiving station and was not therefore in a high bit rate mode. Thus detailed distribution functions were not available. For that reason we have also focused our attention on another event, 10 December 1996, which has the advantage of providing distribution functions, while it exhibits a similar behavior as regards to the comparison between Polar and Geotail. The study is restricted to the following time intervals: from 2050 to 2150 UT for 15 December 1996 and from 1640 to 1820 UT for 10 December 1996. The GSM coordinates of Geotail were approximately $(-23.8,5.2,-1.5) R_{E}$ and $(-25.3,1.2$, $-2.5) R_{E}$, respectively.

\subsection{Ground}

[9] The IMAGE network gives a wide coverage of geomagnetic perturbations associated with currents developing 
over Scandinavia. For 15 December 1996, around 2130 UT, the Geotail footprint drifts towards the East in the vicinity of this network. Using the Tsyganenko 89 model [Tsyganenko, 1989 ] with $K p=3$, one gets the geographic coordinates of the Geotail northern footprint: $71^{\circ}$ in average for the latitude and $15^{\circ}$ in longitude. To help for comparison with Polar images, the respective positions of Geotail (rectangle) and of the ground stations (triangles) have been plotted on a map in a Magnetic Local Time (MLT), Invariant Latitude (INVL) frame of reference (Figure 1a) [Roederer, 1970]. It shows that the location of Geotail footprint fits into the ground network. The X-component (Figure 1b) exhibits a sudden decrease for the stations south of Soroya (SOR) located at $70.5^{\circ}$ geographic latitude. This decrease starts at PEL (Pello, 66 9) at 2051 UT (vertical dotted line). It is remarkably clear that as time elapses, the magnetic perturbation propagates towards higher and higher latitudes up to SOR. Before 2100 , however, there is no typical signature, to the north of SOR, at stations above $70^{\circ} 5$. Thus we are observing the signature of a substorm onset on the $\mathrm{X}$ component, the expansion reaches $\sim 70^{\circ}$. The magnetic signature is less clear on the Y-component (Figure 1c). Later, the activity restarts; two successive periods of reactivation are observed around 2110 and 2123. During these two phases of reactivation, all the stations are concerned, but the signatures are symmetric, i.e., the variation of the $\mathrm{X}$ component is north above BJN (Bear Island) and south below SOR, which indicates that the northern boundary of the westward electrojet is located in this transition region. During the last period of activity, only the high latitude stations above BJN are affected. In summary, the observations are organized around an intermediate latitude between SOR and BJN; first, the activity starts to the South and

\section{2050:54 UT LBHS}

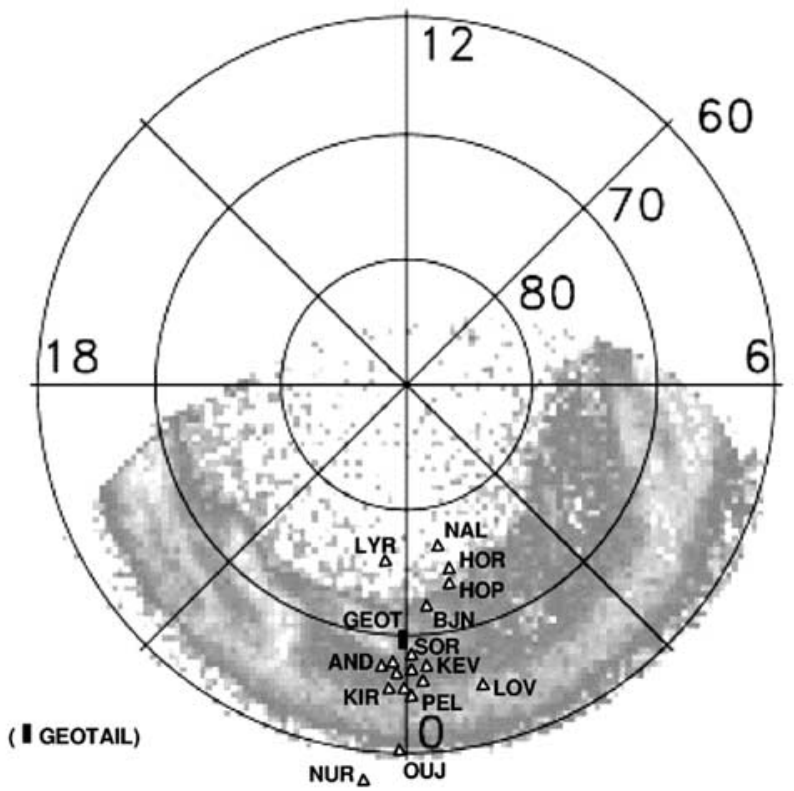

Figure 1a. Map of the ground stations (triangles) with the insertion of Geotail footprint (rectangle) in a MLT-INVL frame of reference.
IMAGE magnetometer network 1996-12-15

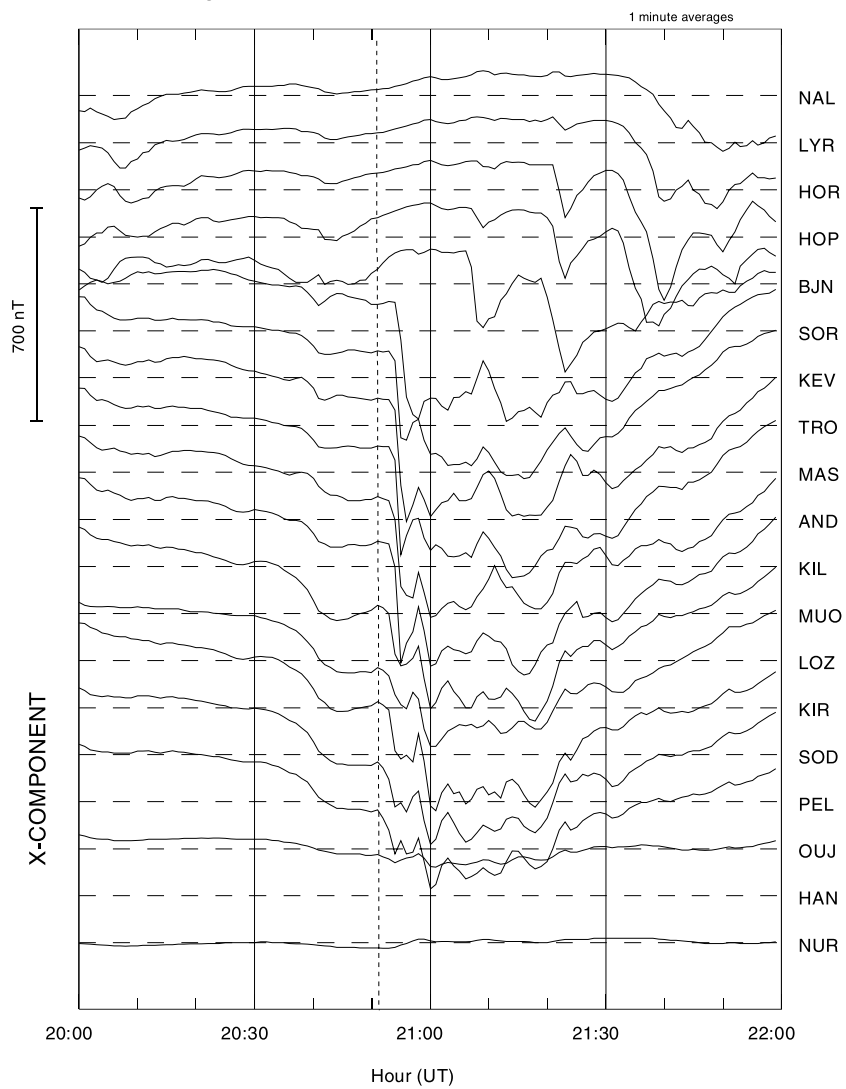

Figure 1b. Ground magnetometer data (X-component) from IMAGE network for 15 December 1996. The latitude of the stations increases from bottom to top. The vertical line shows the substorm breakup seen at low latitude at 2051 UT. Then the perturbation reaches the higher latitudes with a clear delay.

propagates towards the North [Akasofu, 1964] and later the activity takes place mainly at high latitudes. These conclusions are in agreement with the auroral observations on board Polar as shown below.

[10] The second event, 10 December 1996, is not conjugated with the IMAGE network. There only exist lowlatitude measurements already reported by Nagai et al. [1998b].

\subsection{Polar}

[11] The NASA Polar spacecraft, near its apogee, provides global auroral images in two (alternating) UV luminosity bands with $36 \mathrm{~s}$ time resolution [Liou et al., 1997]. For 15 December 1996, Polar images give evidence for the development of a first substorm between 1800 and 1900 UT (also seen on the local AL index but not studied here). Then the magnetosphere recovers its quiet configuration. At 2000 UT there is little activity (low local AL index), especially at low latitude. Later, Polar detects a new series of intensification of auroral forms (local AL index reaches $-500 \mathrm{nT}$ ). From the Polar images the estimated time of the second onset is $\sim 2052$ UT at $\sim 65^{\circ}$ INVL and at the longitude $\sim 2200$ MLT (as it can be seen from the comparison between the images at 2050:54 shown in Figure 6 and the 
IMAGE magnetometer network 1996-12-15

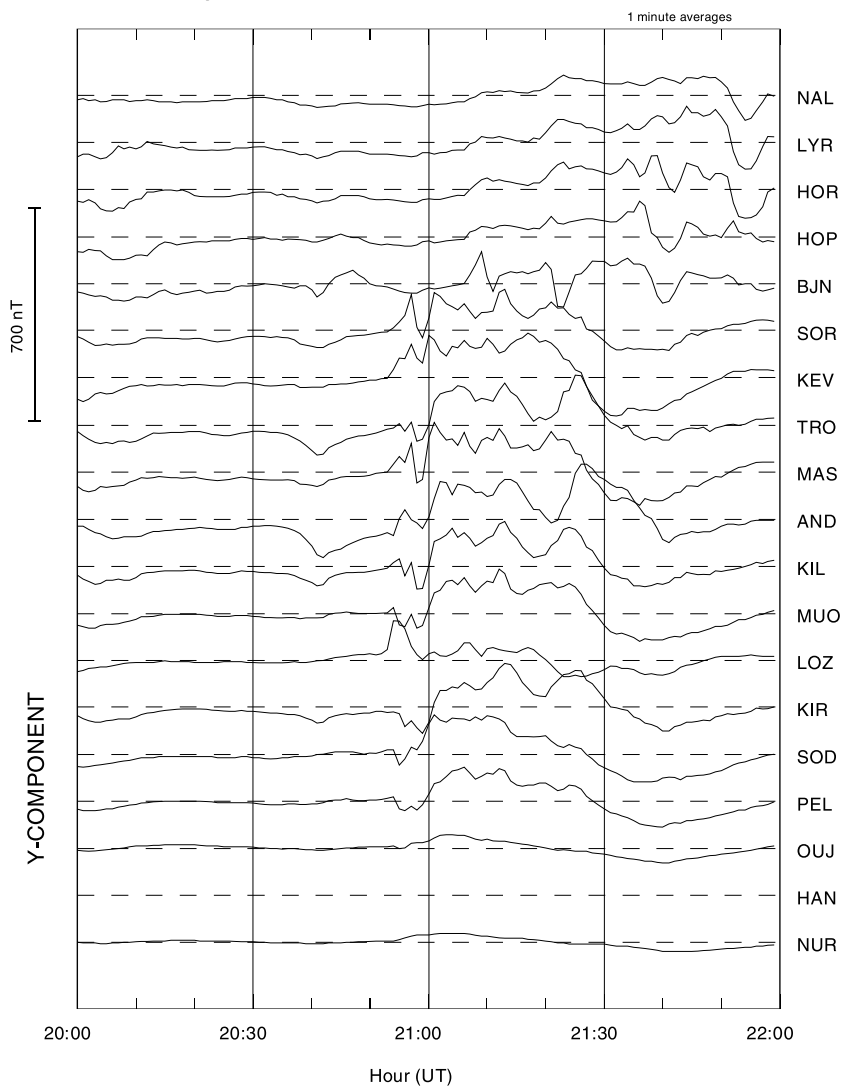

Figure 1c. Same as Figure $1 \mathrm{~b}$ for the Y-component.

first image in Figure 2) and the auroral activity intensifies and rapidly extends towards the west, the east and the north. The large perturbations seen in Figures $1 \mathrm{~b}$ and $1 \mathrm{c}$ reflect the large-scale current disruption corresponding to this substorm. A detailed picture of the development of the expansion phase is shown in Figure 6, while the most characteristic images of the auroral distribution for the whole event are displayed in Figure 2, in the MLT-INVL frame of reference. In this frame, most of the IMAGE network footprints at $2100 \mathrm{UT}$ are localized in the vicinity of the midnight meridian. At 2052:26 and 2052:44 UT (Figure 2), the auroral activity is weak and only reaches the IMAGE meridian at low latitude. In the midnight meridian, the auroral activity expands to the north, from 2052:44 to 2055:48, and reaches a maximum intensity ( $\sim 80$ photons $\mathrm{cm}^{-2} \mathrm{~s}^{-1}$ ) at $\sim 2055: 48 \mathrm{UT}$, followed by a period of decreasing activity with a minimum at $\sim 2105$ UT. As the aurora ceases its poleward progression, which characterizes the end of the expansion phase, the aurora within the bulge often fades noticeably. Before 2108 UT, a high-latitude auroral form intensifies in the evening sector, essentially at a latitude above $70^{\circ}$. After 2108 and before 2123 UT the activity diminishes progressively in the midnight sector. Then at 2123:24 a local, very active auroral disturbance is detected at high latitude around 2300 MLT. Finally, a highlatitude $\left(>70^{\circ}\right.$ INVL) auroral form starts to develop at 2132:36 at the IMAGE network meridian and increases rapidly with a maximum intensity at $\sim 2139$ UT. This highlatitude auroral form corresponds to the high-latitude auro- ral oval already described by Elphingstone et al. [1995]. The surges making up the poleward oval drifts towards the west and leaves the midnight meridian at $\sim 2142$ UT.

[12] The images show that this event consists of two main phases: the substorm starts developing on the most equatorward oval (the main UV oval) and later expands to the north. The poleward oval, covering a wide longitudinal sector at latitudes well above $70^{\circ}$, begins to develop after the end of the expansion phase; successive intensifications of this high-latitude oval occur. This behavior is in complete agreement with earlier papers by Elphingstone et al. [1995]. After reactivations the recovery phase is at $\sim 2132$ UT. The signatures obtained from ground-based instruments substantiate the above conclusions.

[13] The second event, 10 December 1996, presents a similar behavior (data are not shown here but this event has already been described by Nakamura et al. [1998] and Håland et al. [1999]). The auroral activity starts also at low latitude in the midnight sector and expands northward. After this expansion the activity takes place predominantly at high latitude. The difference with respect to 15 December 1996 is the presence of a faint transpolar structure between 1600 and $1700 \mathrm{UT}$.

\section{Geotail Observations: Relation Between the Location of the Auroral Forms and the Flow Velocity}

[14] The Geotail position is especially appropriate for a comparison with the auroras observed on Polar at the same time. For both events, Geotail is located close to the midnight local time, at a radial distance of $\sim 23 R_{E}$ in the vicinity of the center of the current sheet. During the 15 December 1996 event, between 2050 and 2150 UT, Geotail crosses several times the neutral sheet ( $B$ is close to 0 and $B x$ changes its sign). Figure 3 displays from top to bottom the magnetic field components, the ion density and temperature, and the ion velocity components (in GSM coordinates). It is important to notice that the magnetic field at Geotail is small (less than $10 \mathrm{nT}$, except at 2056 ) before the first current disruption at Geotail, (i.e., before 2057 UT) and is very small $(\sim 5 \mathrm{nT})$ after current disruption for $4 \mathrm{~min}$, from 2057 to $2101 \mathrm{UT}$. The density is above $0.1 \mathrm{~cm}^{-3}$. Thus Geotail is located within the current sheet before and during the current disruption which is a rare situation; generally the magnetic field is $\approx 15 \mathrm{nT}$ before the first current disruption, suggesting that the spacecraft is outside the current sheet, as it is the case at 2108 UT.

[15] The behavior of the magnetic field detected on board Geotail will be discussed in more detail in the next section. Nevertheless, it is important to replace these measurements with respect to Polar observations. From 2054 to 2101 UT, $B y$ is oscillating around 0. $B x$ decreases until $\sim 2056(-15$ $\mathrm{nT}$ ) and later oscillates around 0 till $2101 \mathrm{UT}$. Bz starts to increase before 2052 from 2 up to $8 \mathrm{nT}$ at 2056 and decreases afterwards. $B z \approx 0$ at about 2056 and then becomes $<0$. During this phase, Geotail is located in the southern part of the central plasma sheet: the modulus of $B$ is weak $(\approx 5 \mathrm{nT})$ and the density is $\approx 0.15 \mathrm{~cm}^{-3}$. Polar observations allow us to consider that before 2052 UT, the auroral activity is confined at low latitudes; thus the maximum of the current density is still located in the vicinity of the Earth. When the 
UVI 19961215 2052: 26 UT LBHL UVI19961215 2052:44 UTLBHL UVI 19961215 2055:48 UT LBHL.
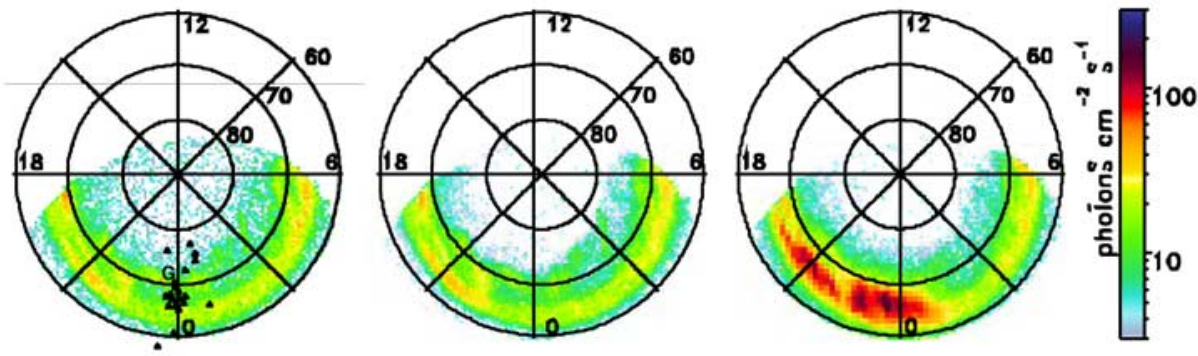

UVI 19961215 2058:52 UI LBHL UVI 19961215 2105:00 UT LBHL UVI 19961215 2108:04 UT LBHL
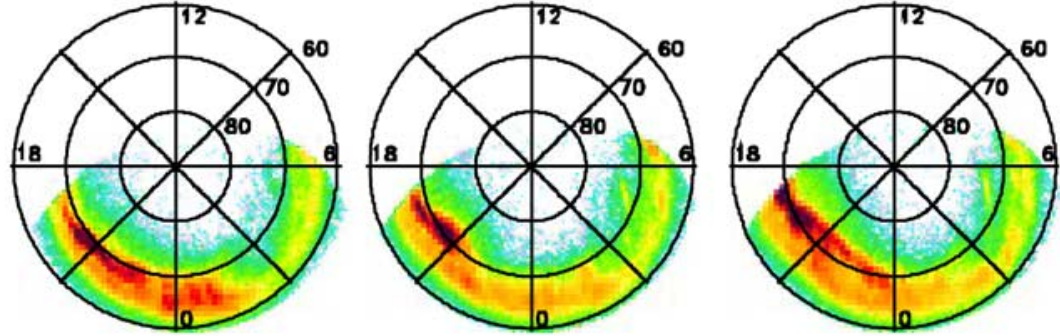

UVI 19961215 2111:08 UT LBHL UVI 19961215 2114:12 UT LBHL UVI 19961215 2120:20 UT LBHL
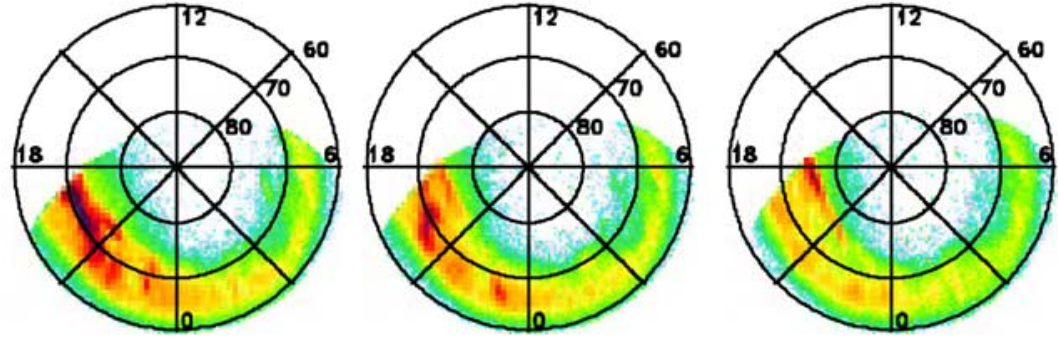

UVI 19961215 2123:24 UT LBHL UVI 10961215 2132:36 UT LBHLUVI 19961215 2135:40 UT LBHL
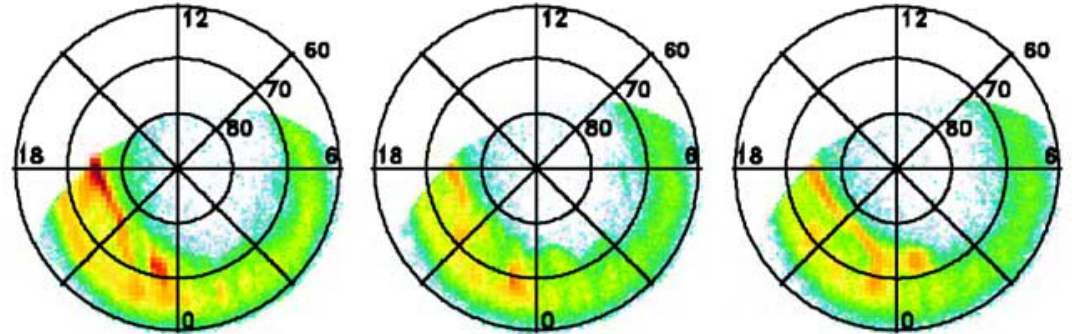

UVI 19961215 2138:44 UT LBHL UVI 19961215 2141:48 UT LBHI UVI 19961215 2144:52 UT L8HL
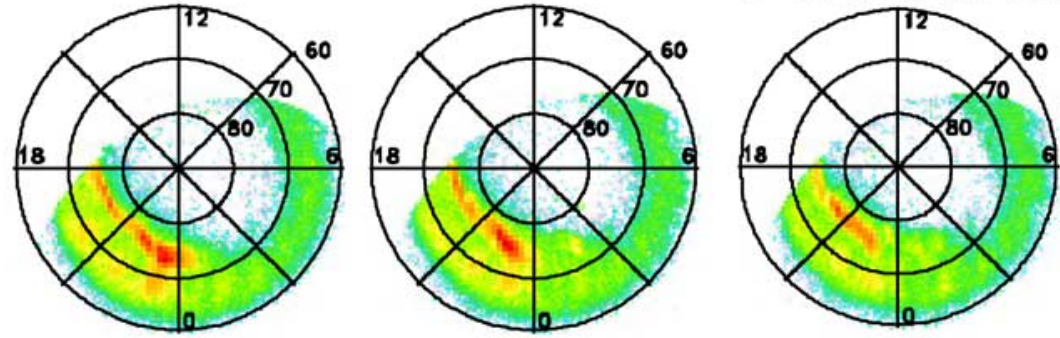

Figure 2. Selection of UVI images (in the LBHL mode) plotted in magnetic coordinates for 15 December 1996. On the first plot the locations of the IMAGE stations are indicated by triangles and the Geotail position by a rectangle.

bulge expands towards the North, corresponding to the time interval between 2053 and 2056, the maximum of the current density is approaching Geotail. It is only after that the bulge has developed that the magnetic field cancels at Geotail. The following periods of negative $B z$ component $(\approx 21: 06$ and $\approx 21: 22$ UT) correspond to a different situation since the spacecraft is located in the lobes (large modulus of $B$ and weak density). 


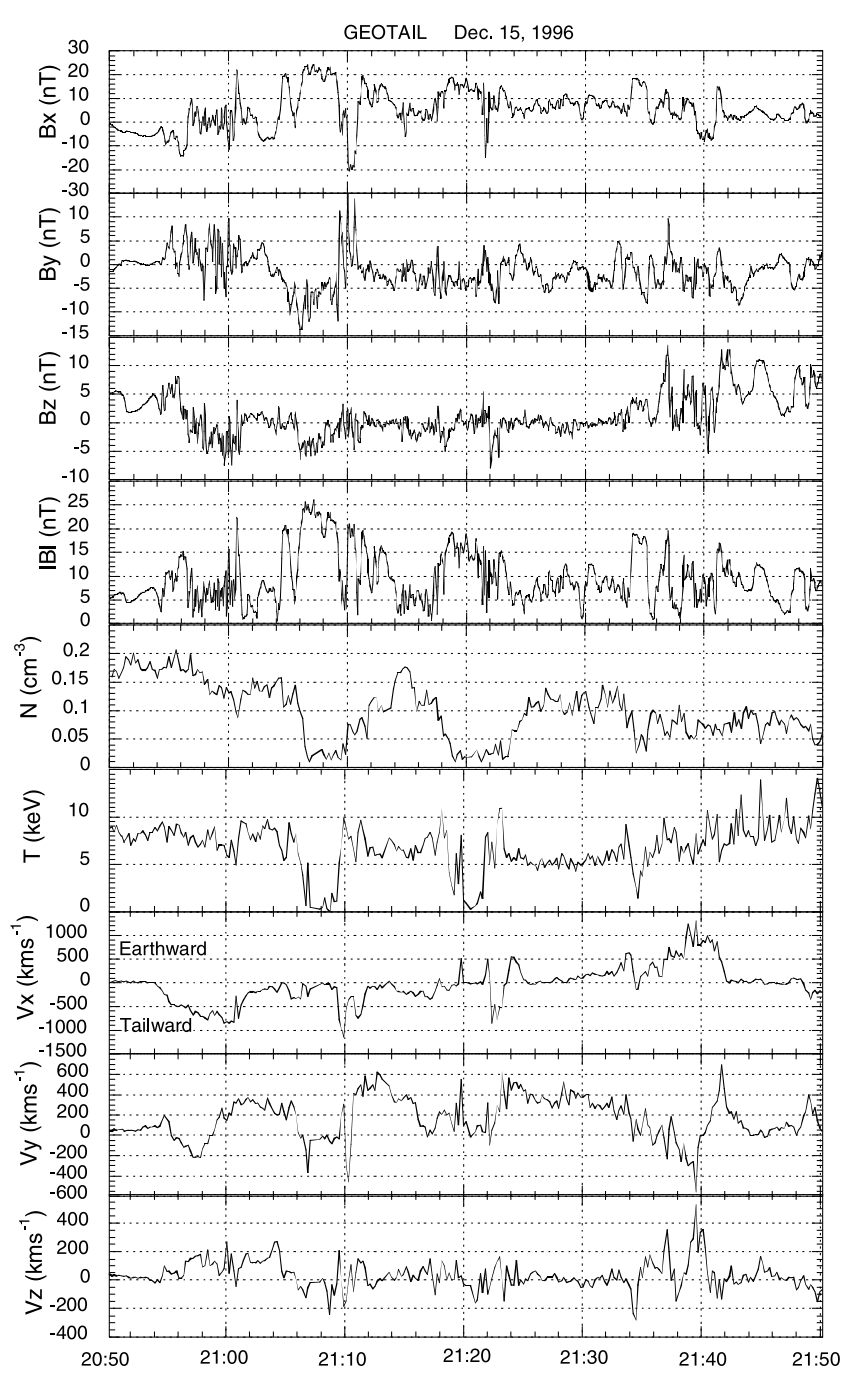

Figure 3. Geotail 3-s magnetic field (three components in GSM and modulus), 12-s density, temperature and ion moments (in GSM) are shown from top to bottom for 15 December 1996.

[16] A series of large bursts in the flow velocity is detected from the velocity measurements (lowest panels in Figure 3); the radial component $V x$ of the ion velocity exceeds $500 \mathrm{~km} / \mathrm{s}$ (and sometimes $1000 \mathrm{~km} / \mathrm{s}$ ) around 2058, 2110, 2123 and 2138 UT. These bursts last 3 to $10 \mathrm{~min}$. The first three velocity bursts have a radial component mainly directed towards the tail $(V x<0)$. Conversely, after 2124 UT the flows are directed earthward. Although $V y$ remains smaller than $V x$, this component reaches values larger than $400 \mathrm{~km} / \mathrm{s}$ during relatively long periods (up to few minutes). We have compared the $V x$ and $V y$ components to the parallel and perpendicular components of the ion velocity (Figure 4). The $V x$ component is predominantly perpendicular (as indicated by the black lines below Figure $4 \mathrm{~b})$ for small values of the magnetic field $(<5$ nT) observed when $B x$ is close to 0 ; while Geotail is in the neutral sheet a radial flow corresponds to a flow perpendicular to Bo. Outside of the current sheet, the velocity is also radial, but it corresponds to field-aligned moving ions. This is what is observed at different stages of this event (blackened areas in Figure 4a). When $B x$ exceeds $\pm 10 \mathrm{nT}$ with a density $>0.1 \mathrm{~cm}^{-3}$, Geotail is likely no longer in the current sheet but still in the plasma sheet. Not surprisingly, the $V y$ component is predominantly perpendicular to the magnetic field. The periods indicated by thick black lines in Figure $4 \mathrm{~d}$ correspond to a duskward propagation $(V y>0)$, as pointed out by Paterson et al. [1998]. Notice that during the periods of predominantly westward velocity, $B x$ is $\sim 10 \mathrm{nT}$ while $B z$ is close to 0 , the density around $0.1 \mathrm{~cm}^{-3}$, the ion temperature is stable, $\sim 8.5 \mathrm{keV}$ at $\sim 2105, \sim 7.5 \mathrm{keV}$ at $\sim 2113$, and $5.5 \mathrm{keV}$ at $\sim 2127 \mathrm{UT}$.

[17] It is now interesting to discuss the behavior of the ion flow in connection with the development of the auroral activity, as inferred from IMAGE network and Polar. The position of the Geotail footprint has been estimated via the Tsyganenko model to be around $\sim 70^{\circ}$ latitude near midnight local time. If one compares the position of the Geotail footprint with the position of the auroras, one notices the following. Until 2054, Geotail detects no flow velocity, while the low-latitude auroral form starts at $\sim 2052$ (see image 1 in Figure 2) and intensify around 2130 MLT for an invariant latitude $\sim 65^{\circ}$. Then suddenly the bulge extends simultaneously towards the west, the north, and the east. As the bulge expands to the north and approaches Geotail footprint at $\sim 2054$ UT (see Figure 6), Geotail starts to detect an increase in the ion flow velocity. Afterward, the auroral activity continues to develop to the north (and to the east) with a larger intensity. At 2055:48 for example, the emission around midnight is strong and the velocity measured on board Geotail reaches $500 \mathrm{~km} / \mathrm{s}$. Then the Geotail footprint, predicted via the Tsyganenko model, is located at the poleward edge of the auroral activity that is close to or within this northern structure. From 2054 to 2102 UT the ion flow velocity is tailward, which suggests that the acceleration of the flow occurs earthward of Geotail. However, the change in the sign of $B z$, from $B z>0$ to $B z<0$ does not affect the outward direction of this flow. This is consistent with the low latitude of the auroral bulge during this time period and with the magnetograms shown in Figure 1. Although Geotail was located at smaller distances from the Earth $\left(10-15 \mathrm{R}_{E}\right)$, comparisons between Polar and Geotail have led Frank et al. [2001a, 2001b] to the similar conclusions.

[18] Before comparing Geotail and Polar observations, it is important to give an estimate on the accuracy in the determination of the location of the Geotail footprint and on the restitution of the UVI images in the MLT/INV frame. Geotail is located at about $23 \mathrm{R}_{E}$. We have computed its footprint for different sets of parameters. For $K p=3$ and for the different Tsyganenko models the geographic latitude of the Geotail footprint varies between 71 and $72^{\circ}$. For Tsyganenko 89 with $\mathrm{Kp}$ varying from 0 to 6 this value decreases from $72^{\circ} 7$ to $70^{\circ} 3$. Thus there is a difference of $2^{\circ}$ for large variations of the magnetic activity. Therefore one can estimate that the accuracy is not better than 1-2 degree. Concerning Polar, the wobble is in the noon-midnight direction, and in that direction the uncertainty can be $1-$ $1.5^{\circ}$. There is no uncertainty on the timing but in locating the position. This uncertainty on the location could have had an effect on the timing if Polar was used alone. Since we are combining Polar and a ground-based network, the comparison of Geotail/ground-based (including Polar) observations is not affected by this problem. 
GEOTAIL Dec. 15, 1996

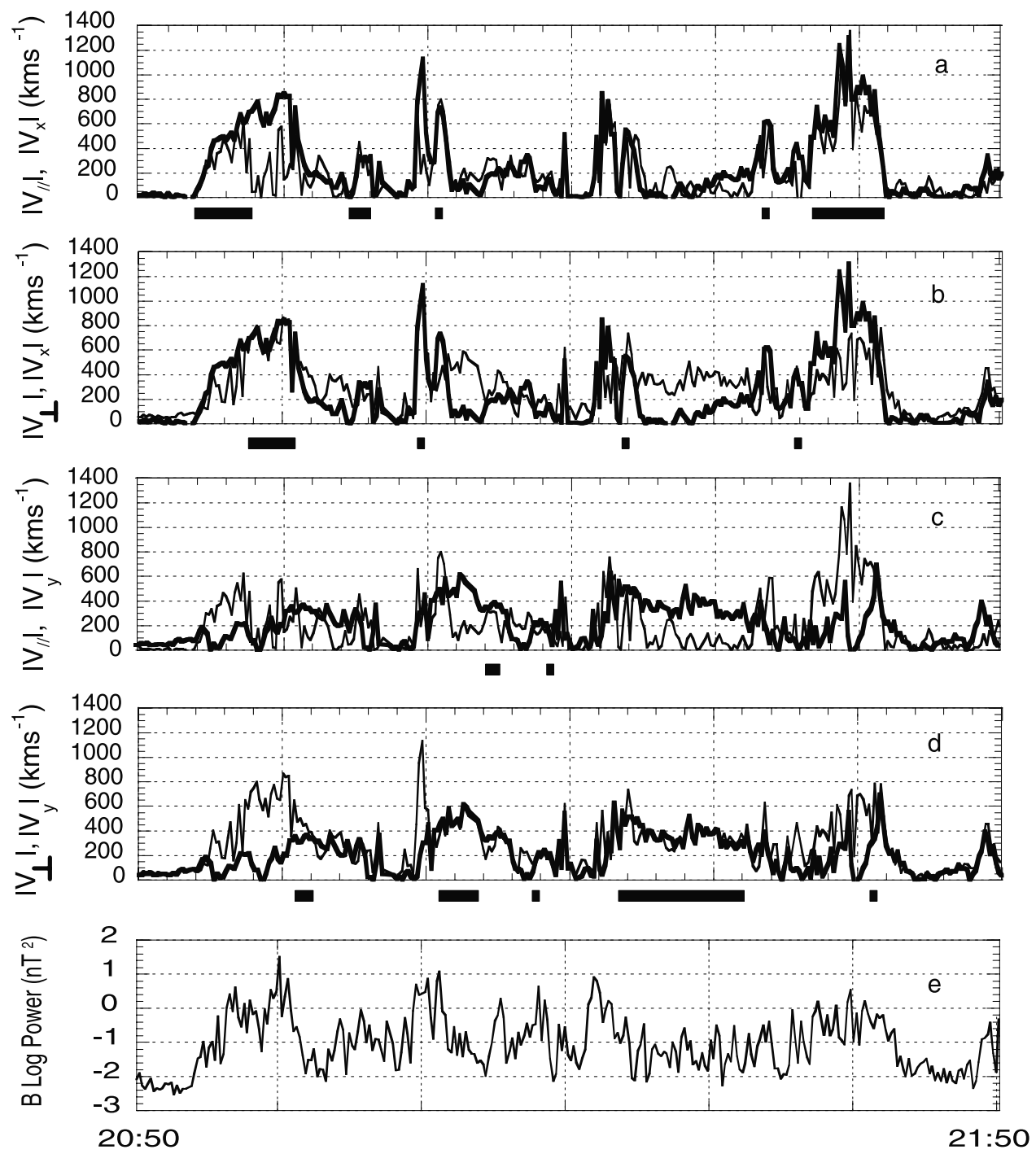

Figure 4. Figures $4 \mathrm{a}-4 \mathrm{~d}$ show different components of the ion velocity. (a) X-component [radial] (thick line) and parallel (to Bo) (thin line) components; (b) radial (thick line) and perpendicular (to Bo) (thin line); (c) Y-component [azimuthal] (thick line) and parallel (thin line); (d) azimuthal (solid line) and perpendicular (thin line). The dark lines below the panels indicate the periods when the velocity component is dominantly parallel or perpendicular. (e) The integrated power of the $\mathrm{Bz}$ magnetic component of the waves (computed over $12 \mathrm{~s}$ from the high bit rate: $16 \mathrm{~s}^{-1}$ ) between 0.08 and $8 \mathrm{~Hz}$.

[19] At 2120 UT the auroral intensity seen by Polar is still south of Geotail footprint; the flow detected by Geotail at $\sim 2122$ is still tailward. A few minutes later, at $\sim 2123$, an auroral form expands to higher latitudes (above $70^{\circ}$ ) at 2300 MLT; at the same time, the Geotail ion flow direction reverses to earthward. This is even clearer around 2135 UT. From $\sim 2132$ to $2135: 30$ the auroral structure develops over a wide range of longitude and to the north of Geotail footprint. During this time interval the flow is now earthward, thereby indicating that the source region is now located beyond the position of Geotail. The velocity reaches a maximum at $\sim 2139$ UT, when the intensity of the poleward auroral oval was maximum $\left(>80\right.$ photons $\left.\mathrm{cm}^{-2} \mathrm{~s}^{-1}\right)$ in the vicinity of the Geotail longitude (but at a higher latitude). When the auroral form fades away near Geotail footprint (see the last images in Figure 2), the velocity measured on board Geotail sharply decreases. Thus there exists a relation between the position of Geotail, the source of the auroral emission, and the flow direction. The more intense the auroral precipitation, the stronger is the ion flow velocity. Fast flows are observed when there is a bulge in the vicinity of the spacecraft footprint. The flow is either earthward or tailward depending on whether the bulge is at a lower or a higher latitude than the footprint. A similar behavior has been evidenced for 10 December 1996.

[20] Having established the relationship between the occurrence of fast flows in the plasma sheet and the development of the auroral activity, it is important now to investigate the link between these two sets of observations. We will show in section 5 that this relation is mediated by waves around the proton gyrofrequency, detected at the same time as the flow velocity. When fast flows are 
observed, rapid fluctuations are superimposed on the DC magnetic field; this relationship between strong electromagnetic fluctuations and ion velocities is confirmed by plotting the power of the $B z$ component integrated between 0.08 and $8 \mathrm{~Hz}$ in Figure 4e. The occurrence of large ion flow velocities along the $\mathrm{x}$ component follows the intensification of the waves. The relationship between waves and particles will be further discussed in section 6 .

[21] The 10 December 1996 event presents a similar behavior. It has already been studied by Nakamura et al. [1998] and Hailand et al. [1999]. The event has a short duration and before and after the current disruption, $B x$ is $\sim-20 \mathrm{nT}$. Thus the spacecraft was not located in the current sheet.

\section{Magnetic Variations Induced by the Tail Current Sheet}

[22] In this section we describe the magnetic signature of the current sheet, which plays a major role in the dynamics of the tail during substorms, especially during the expansion phase. The signature of the magnetic perturbations detected by auroral zone magnetic observatories has been already extensively studied [Baumjohann et al., 1981]. We use the information provided by ground-based observations (intensification of ionospheric currents) and Polar images (auroral brightening) showing that the substorms studied here start at low latitude and then expand towards the north; that is, the source of the electron precipitation is near the Earth and then moves tailward. The impact of the auroral precipitation is seen first at Pello (geographic latitude: $66^{\circ} 9$ ) and then at Soroya $\left(70^{\circ} 5\right)$ with a delay of $\sim 3 \mathrm{~min}$. The northern motion has an average velocity of $2.2 \mathrm{~km} / \mathrm{s}$. The mapping of these two stations in the tail corresponds to a distance of about 15 $\mathrm{R}_{E}$, giving a velocity of $530 \mathrm{~km} / \mathrm{s}$ projected in the tail.

[23] Another estimation of the velocity in the tail can be derived from the conservation of the magnetic flux along the field lines. The magnetic field measured on the ground is $\sim 50,000 \mathrm{nT}$ and in the midtail is $\sim 5 \mathrm{nT}$. The deformation of the flux tube in the midtail (elongation in the radial direction) leads to correcting the ratio of the fields by its square root. Thus the velocity in the tail will be $100 \times 2.2=$ $220 \mathrm{~km} / \mathrm{s}$. These two rough estimates of the projection of the velocity of the northward auroral motion converge to values of a tailward velocity of the order of few hundreds of kilometers per second.

[24] It is also well established that nearly simultaneously at synchronous orbit and beyond, near midnight the plasma sheet expands as the magnetic field rotates from a tail-like to a more dipolar configuration, while the electron flux and to a lesser extent the ion flux increase by a large factor. Using ISEE or IMP-8 data, Jacquey et al. [1991] and Ohtani et al. [1992] showed that the dipolarization/current disruption region expands from the near-Earth region to the tail with a velocity of the order of $200-300 \mathrm{~km} / \mathrm{s}$. Then it is logical to associate the northward expansion with the tailward motion of the dipolarization. Thus during the expansion phase, the near-Earth part of the current sheet is progressively destroyed. Changes in the location (radial size) of the current sheet produce magnetic variations that depend on the position of the spacecraft with respect to the current sheet. Assuming an uniformly distributed current sheet with a finite extension in the radial direction $X$, between $X_{1}$ and $X_{2}$ as shown in Figure 5 and a width $\pm \Delta Z$ along the $Z$ direction, the components $X$ and $Z$ of the magnetic perturbations produced by the current sheet at a given point $\left(X_{0}, Z_{0}\right)$ are written as

$$
\begin{gathered}
\delta B_{x}=\frac{\mu_{0} J_{y}}{2 \pi} \int_{-\Delta Z}^{\Delta Z}\left\{\operatorname{Arctg} \frac{X_{1}-X_{0}}{z-Z_{0}}-\operatorname{Arctg} \frac{X_{2}-X_{0}}{z-Z_{0}}\right\} d z \\
\delta B_{z}=\frac{\mu_{0} J_{y}}{4 \pi}\left\{\int_{-\Delta Z}^{\Delta Z} \ln \left[\left(\frac{X_{1}-X_{0}}{z-Z_{0}}\right)^{2}+1\right] d z\right. \\
\left.-\int_{-\Delta Z}^{\Delta Z} \ln \left[\left(\frac{X_{2}-X_{0}}{z-Z_{0}}\right)^{2}+1\right] d z\right\} .
\end{gathered}
$$

After integrating over the thickness of the current sheet, one gets the variations of the magnetic perturbation with a normalization factor $\mu_{0} J_{y} / 2 \pi$. We have computed the variations of $\Delta B$ for a given altitude; for the regions above or below the equator, the $\delta B_{x}$ variations are symmetric with respect to the equator, while the $\delta B_{z}$ variations are unchanged. Both components are null in the center of the sheet. Here $\delta B_{x}$ is maximum at the surface of the sheet, except in the vicinity of the borders of the sheet at $X_{1}$ and $X_{2}$ while $\delta B_{z}$ is maximum for these positions. The modifications of a dipolar field produced by the presence of a thin current sheet $\left(\Delta Z= \pm 0.2 R_{E}\right)$ are presented in Figure 5. The $B x$ and $B z$ components are plotted for the altitudes $z=0$ and 1 .

[25] In Figure 5a the current sheet gets close to the Earth and the field lines are stretched; $B z$ component is $>0$ whatever the distance $x$. In Figure $5 \mathrm{~b}$ the main change is the increase of the $B x$ component for $z=1$, as a consequence of an increase of the current density by $50 \%$, while the size of the current sheet is the same as for Figure 5a. Thus Figure $5 \mathrm{~b}$ illustrates the effect of the intensification of the current density. In Figure $5 \mathrm{c}$ the internal part of the current sheet has been eroded; the $B z$ component becomes negative in the vicinity of the internal border of the current sheet, as a consequence of the disruption of the earthward part of the current sheet; for $z=0$, the topology of the field lines exhibits an $\mathrm{X}$ point close to the Earth at $\sim 12 R_{E}$ and an O point further out. Similarly, for $z=1$, the $B x$ component decreases near the inner border of the current sheet but remains positive. In Figures $5 \mathrm{~d}$ and $5 \mathrm{e}$ the current sheet is more and more eroded, and the $\mathrm{X}$ and $\mathrm{O}$ points move further out in the tail at the same time as $B z$ gets more and more

Figure 5. (opposite) Deformation of the field lines expected in the tail when the TCS is eroded. The thickness of the current sheet is fixed ( $\left.\Delta \mathrm{Z}= \pm 0.2 R_{E}\right) . B x$ (thin curve) for $z=1 \mathrm{R}_{E}, B z$ (thick curve) for $z=1 \mathrm{R}_{E}$ and $B z$ (thick dotted curve) for $z=0$ are also plotted. $B x=0$ (thin dashed line) at $z=0$. From a to $\mathrm{b}$ the current increases. Then from $\mathrm{b}$ to $\mathrm{c}$ the inner part of the TCS is eroded. On $d$ and e the erosion continues, which leads to a TCS detached from the Earth magnetic field. Final magnetic configuration is shown on $\mathrm{f}$. During phase a the current intensity is prominent in near-Earth plasma sheet and Geotail detects a positive Bz, while during phase e the maximum of the intensity of the sheet is located tailward to Geotail and $\mathrm{Bz}$ is negative at Geotail. During the phase d Geotail is in the vicinity of the center of the TCS (O point at Geotail). 
(a)
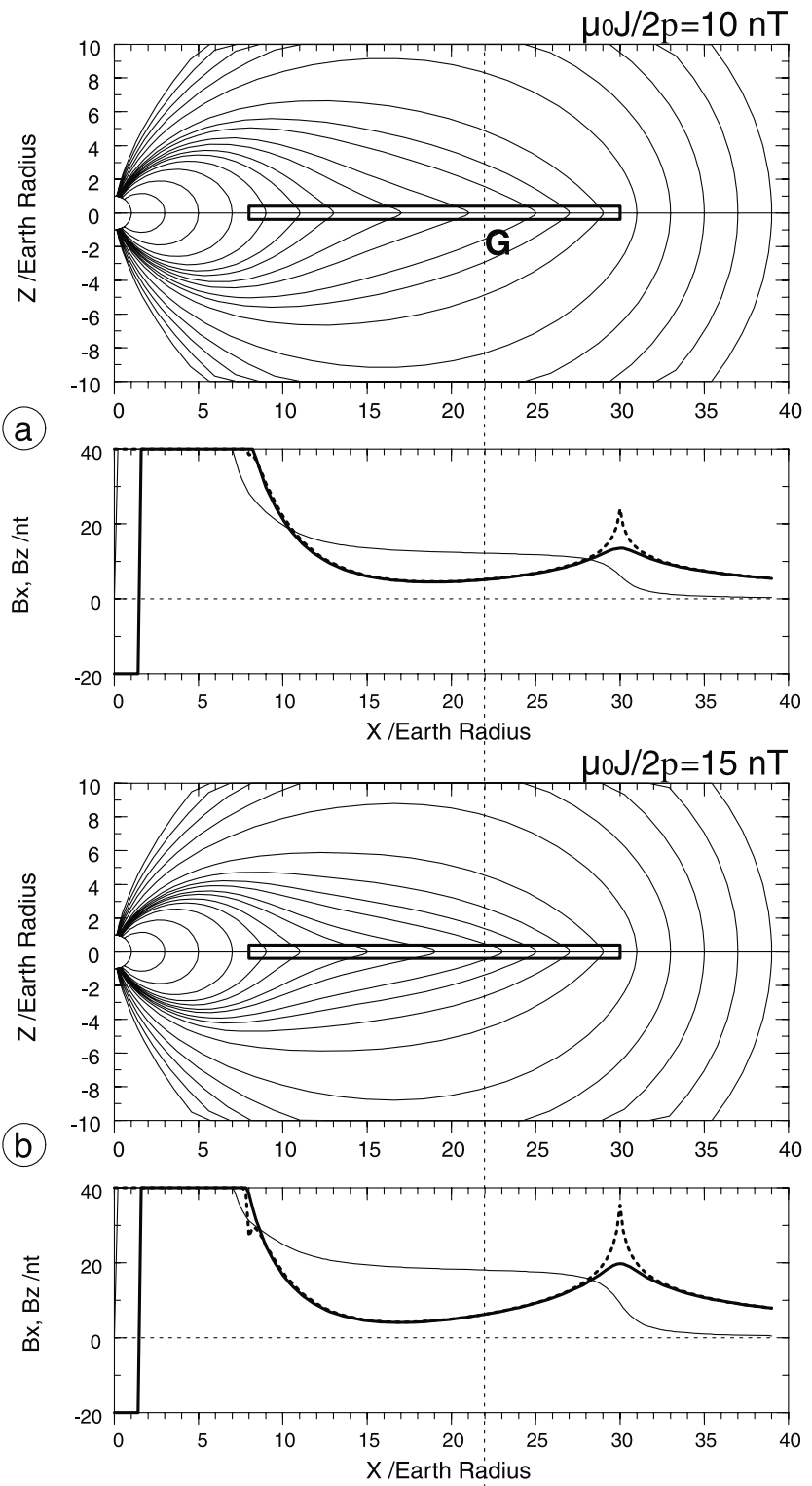

$\mu_{0} \mathrm{~J} / 2 \mathrm{p}=15 \mathrm{nT}$
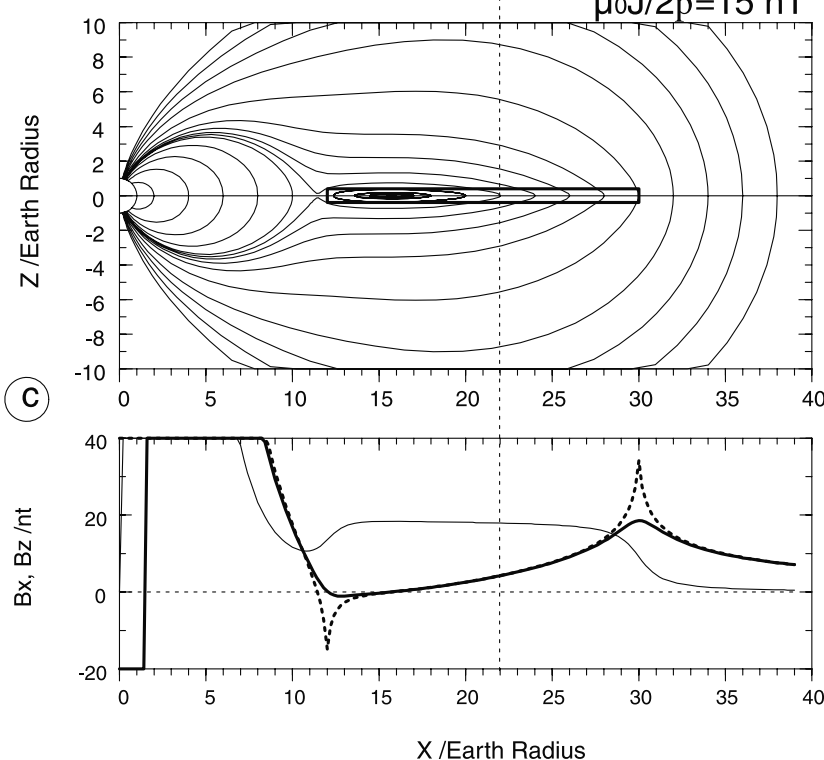

$\mu_{0} \mathrm{~J} / 2 \mathrm{p}=15 \mathrm{nT}$
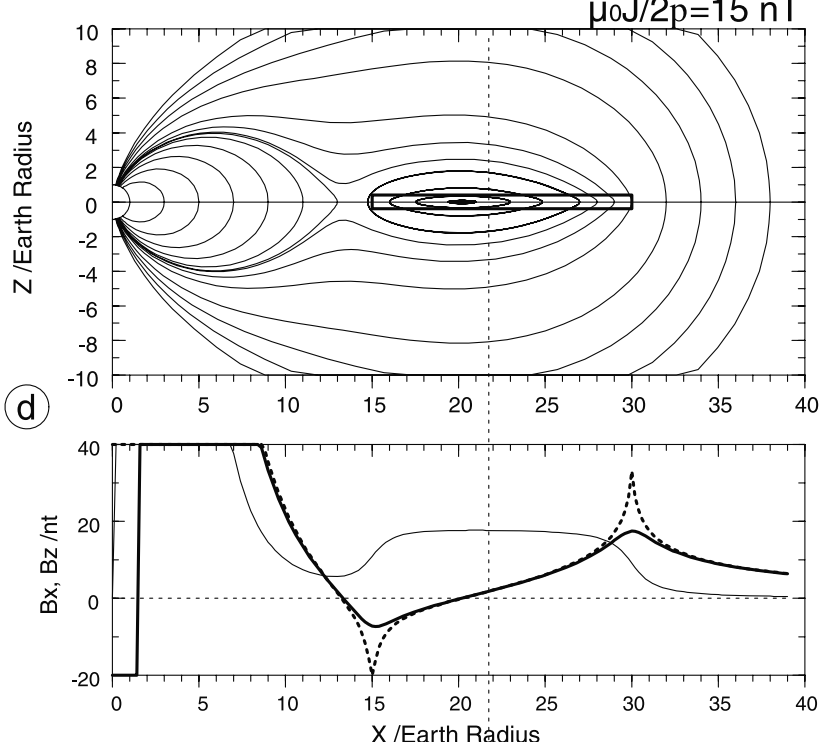

$\mu_{0} \mathrm{~J} / 2 \mathrm{p}=15 \mathrm{nT}$
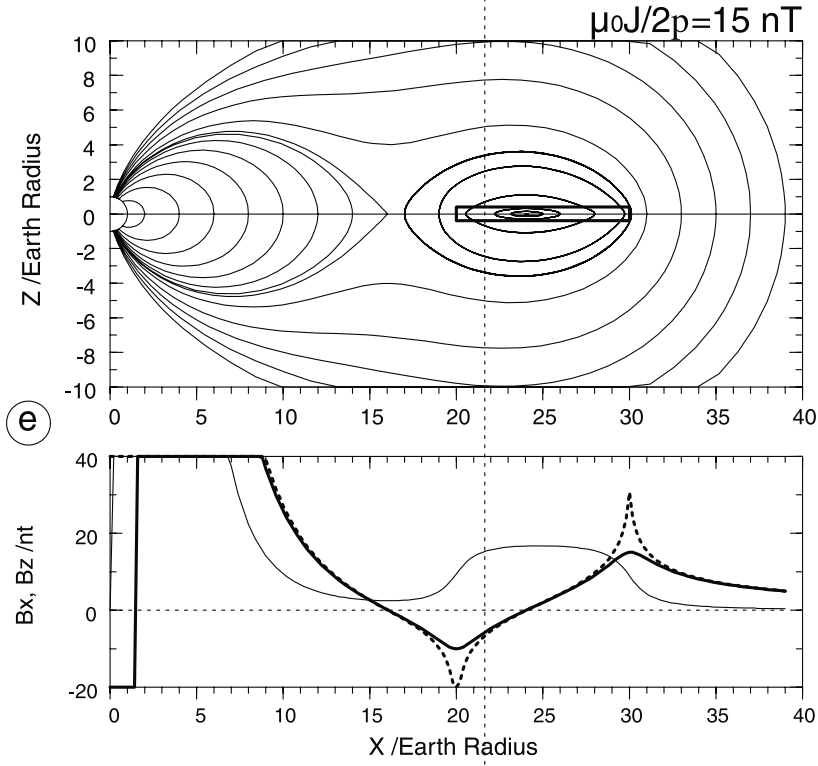

$\mu_{0} \mathrm{~J} / 2 \mathrm{p}=15 \mathrm{nT}$
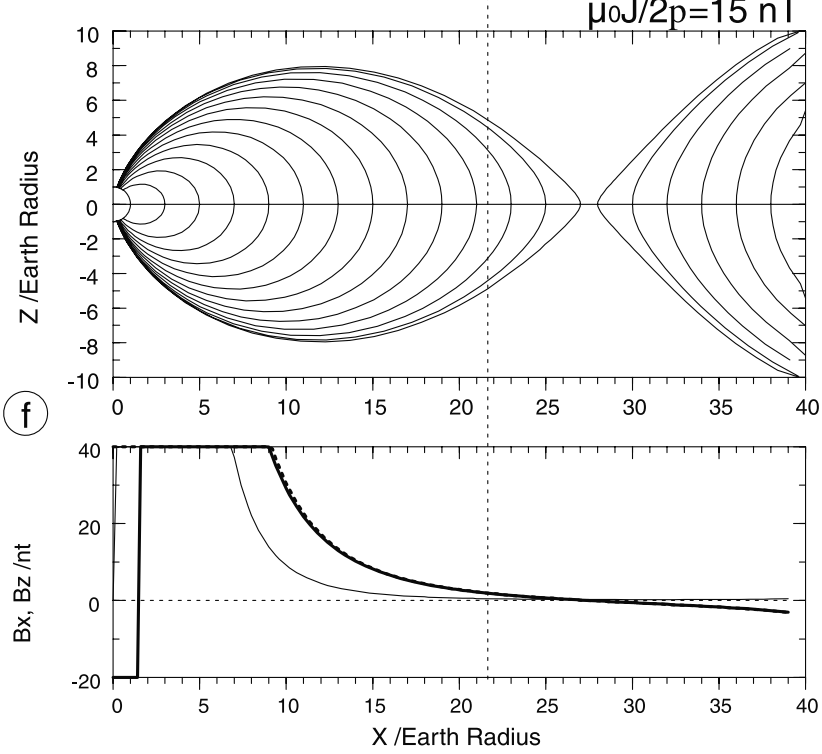
negative for $z \approx 0$. For $z=1$ the $B x$ component progressively decreases in the earthward region of the $\mathrm{X}$ point. For a current sheet far in the tail $\left(x>45 R_{E}\right)$, the $\mathrm{X}$ point is far in tail and the $B z$ component is again $>0$ in the region earthward of the $\mathrm{X}$ point.

[26] This oversimplified model (nonself-consistent) gives the main tendencies of the variations of the magnetic field observed in the midtail when a substorm develops. The application of this model to the Geotail observations is developed in the following section.

\section{Application of the Model}

[27] We have gathered simultaneous observations taken while a substorm developed in the magnetospheric tail. The problem we are faced with is to build a scenario describing these observations. Let us summarize the observations. Figure 6 gathers the observations made simultaneously on the ground, with Polar imager and on board Geotail during the expansion phase of 15 December 1996.

\section{1. $2051 \mathrm{UT}$}

[28] On Figure 6b, the $x$ component of the midlatitude station (Pello) starts decreasing at 2051 UT, which suggests that a thin current sheet (TCS) is formed close to the Earth. On Polar, before 2052 UT (see Figures 2 and 6), the intensification of the auroral forms occurs in the evening sector at relatively low latitude (well south of Geotail footprint). The corresponding magnetic field configuration is presented in Figure 5a. At the Geotail distance $(x \sim 23$ $\left.R_{E}\right), \mathrm{Bz}$ is positive and $\mathrm{Bx}$ could be either positive or negative depending on the position of Geotail with respect to the magnetic equator. At 2051, Geotail is located below the equator. Geotail footprint is east of the main activity and at a higher latitude; no flow is observed.

\subsection{From 2051 to 2054 UT}

[29] The auroral form develops and passes the midnight meridian at $\sim 2054$. During this time interval, the TCS intensifies. The intensification of the TCS is taken into account in Figure 5b, which shows an increase in $|B x|$ and $|B z|$ components at the Geotail distance in agreement with the magnetic perturbations seen in Figures $6 \mathrm{c}$ and $6 \mathrm{e}$, yet $B z$ remains $>0$ until Geotail location (dotted vertical line) and beyond. Later, correspondingly the auroral pattern begins to expand to the north, and towards Geotail longitude. Fast flows are not yet observed.

\subsection{At 2054}

[30] The auroral form reaches the Geotail longitude and expands to the north, reaching Sørøya (Figure 6a). The erosion of the inner part of the TCS leads to a reduction in $B z$ and even to a small region with negative $B z$ at $\sim 12 R_{E}$ (see Figure 5c). At the Geotail distance, $B x$ and $B z$ are stable. The development of a negative $B z$ near the Earth leads to the start of the development of a tailward ion flow velocity, as observed in Figure $6 \mathrm{f}$.

\subsection{From 2054 to 2056 UT}

[31] The bulge develops towards the North, indicating that the current disruption progresses towards the tail. The TCS is progressively eroded over a broad region as shown in Figure $5 \mathrm{~d}$. Then $B z$ is negative from 13 to $19 R_{E}$. Neutral points are formed ( $\mathrm{X}$ and $\mathrm{O}$ ). The TCS disruption still produces Ey westward; following the electric observations made also on board Geotail, Tu et al. [2000] suggest that "the dipolarization may also contribute to the formation of strong duskward electric fields in the inner tail." Thus the flow is tailward because $B z$ is negative ( 13 to $19 R_{E}$ ). At Geotail, Bz is still positive, but the magnetic field being disconnected from the Earth's dipole, the plasma which is moving tailward at 13$19 R_{E}$ also moves tailward at $23 R_{E}$ in spite of a positive $B z$ ( $B x$ is unchanged). Intense waves are observed (Figure $6 \mathrm{~g}$ ).

\subsection{UT}

[32] The bulge has reached the Geotail footprint. As the erosion of the TCS continues, Figure 5e shows that $B z$ becomes negative at Geotail because the center of the TCS is beyond Geotail. Furthermore, when the TCS passes the Geotail position, $B x$ decreases rapidly. Again the observations depict the same tendency since as long as $B z$ is negative, $B x$ is in average null. The flow on Geotail is still tailward but now with a negative $B z$. Intense waves are observed.

\subsection{UT}

[33] The auroral structure is now located at a latitude above Geotail footprint (Figure 2). Thus the TCS is eroded further out in the tail. The magnetic field configuration is presented in Figure 5f. The $\mathrm{X}$ point is beyond Geotail. $\mathrm{Bz}$ is again positive. Ey is westward and the flow is earthward, in agreement with Geotail measurements. Thus a very simple current sheet model where the current is progressively eroded at the earthward edge (which produces a westward Ey) can reproduce the main features of the combined observations.

[34] In spite of its simplicity, the model proposed above is able to give an account of the multiinstrument observations. It is a two-dimensional model, which does not include the variations in the $y$ direction. However, we know that the propagation of the current sheet and of the dipolarization/ current disruption produces a modification of the local currents, more precisely parallel currents intensify. These currents can be inferred from the $B y$ component (Figure 6d). The fact that the ion velocity is predominantly parallel to the magnetic field during the expansion phase (Figure 6f) suggests that the ions carry at least part of the parallel current. During the same time interval, the intensity of the waves (Figure 6g) follows very well the variations of the ion parallel velocity (red line in Figure 6f). This suggests that the waves provide an effective dissipation for parallel currents, which implies a change in the perpendicular current and in the magnetic configuration. As the TCS passes by Geotail, $B z$ gets negative and the plasma can flow freely as a wind. We have checked that when the waves have a large intensity, the ion velocity is superalfvenic. At $\sim 2056$, the ion velocity is predominantly perpendicular to the magnetic field. It is only at that time that Geotail detects a convective flow.

[35] The scenario presented in this paper involves waves around the proton gyrofrequency. They are studied in section 6 .

\section{Relationship Between Flow Velocity and Waves Around the Proton Gyrofrequency}

[36] Another striking observation during the development of this substorm concerns the intensification of the waves 


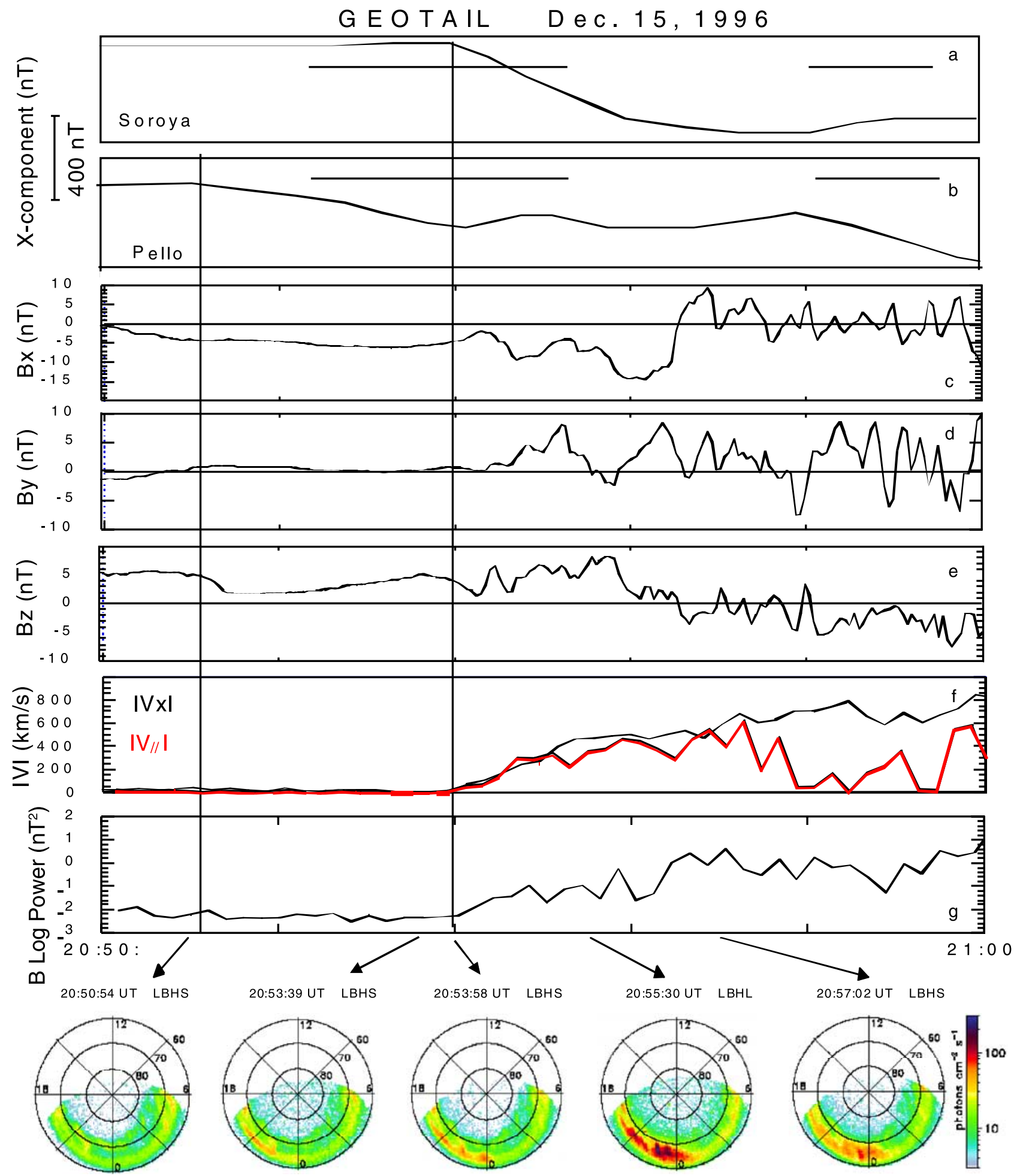

Figure 6. (a) Stacked plots of a high-latitude (Sørøya) and (b) midlatitude (Pello) 1-mn magnetometer data, (c-e) Geotail 3-s magnetic field, (f) 12-s X-component [radial] (black line) and parallel (red line) ion velocities, and (g) integrated power (over $12 \mathrm{~s}$ ) of CDA waves for the 15 December 1996 breakup. On the bottom, Polar images mainly in the LBHS mode complete the selection presented in Figure 2 . The auroral activity approaches Geotail footprint at $\sim 2055: 30$, but the ion flow velocity starts increasing before (2054). Simultaneously wave intensity grows. 
with frequencies of the order of the proton gyrofrequency. The amplitude of these fluctuations progressively increases with the ion velocity (Figure 4). Notice that the power of the fluctuations exceeds $1 \mathrm{nT}^{2}$ during $5 \mathrm{~min}$, during the expansion phase. Similar waves have been observed on GEOS-2 [Perraut et al., 1993] and INTERBALL-2 [Perraut et al., 1998]. These waves have a broad spectrum exceeding the proton gyrofrequency $\mathrm{F}_{\mathrm{H}}+$, but most of the energy is below $\mathrm{F}_{\mathrm{H}^{+}}$[Perraut et al., 2000a]. They have a parallel electric field component $\delta \mathrm{E}_{/ /}$that can accelerate the electrons in the direction parallel to $B o$, via Landau resonance [Perraut et al., 2000b]. Parallel diffusion is a very efficient process, and the electrons are heated as they move along the field lines. Here we would like to give an example of particle distribution functions which illustrates electron acceleration via waves. According to Perraut et al. [2000a], these waves are easily destabilized by field-aligned currents. We do observe ions flowing along the field lines, for instance between 2054 and 2056 UT, but we can hardly determine the electron velocity, because the expected drift velocity ( $\leq V_{\text {thi }}$, the ion thermal velocity) is much smaller than the electron thermal energy. Thus it does not seem to be possible to confirm the existence of a parallel current from Geotail measurements.

[37] During the 15 December 1996 event, Geotail was not in a favorable position with respect to the tracking station; hence high-resolution data are not available for building particle distribution functions. Thus we have selected 10 December 1996, when Geotail was in the high bit rate mode. We have concentrated our investigation of the ion distribution function on the first isolated significant event, between 1650 and 1700 UT. It has been observed on Polar and identified as a pseudobreakup [Nakamura et al., 1998] and more precisely as a flux rope [Håland et al., 1999]. It is localized and lasts less than $3 \mathrm{~min}$. The corresponding set of parameters recorded on board Geotail is displayed in Figure 7. Geotail encounters a typical plasma sheet (density $\sim 0.5 \mathrm{~cm}^{-3}$ ) but, unlike the 15 December 1996 event, it is not located inside the current sheet before the event. Nevertheless, high-speed tailward flows $(500 \mathrm{~km} / \mathrm{s})$ are observed. The variations of wave intensity follow the variations of the ion velocity. The power of the waves reaches $1 \mathrm{nT}^{2}$ during a short time interval. The distribution functions are integrated over 4 spin intervals, i.e., $12 \mathrm{~s}$ in order to get a significant counting of particles. During these $12 \mathrm{~s}$, however, the magnetic field can rapidly fluctuate (on high resolution data not shown) which raises questions as to the validity of the determination of the momentum. The assumption of a steady medium during the measurement of the distribution function (12 s) is not granted as already underlined by Parks et al. [2001]. Fluctuations with $\delta B / B \sim 1$ are recorded. Thus we have indicated the time intervals (blackened area) in Figure 7 corresponding to fast magnetic field changes. The ion distribution function, displayed in Figure 8, corresponds to time intervals when the $B$ variations are small, which gives a good confidence in the calculation of the moments. The ion distribution clearly shows the presence of a field aligned beam, mainly in the tailward direction with a velocity $>400 \mathrm{~km} / \mathrm{s}$ (i.e., $2 \mathrm{keV}$ ). There is also a shift in the distribution function, in the $E \times B$ direction, which is approximately along $y$. The drift velocity is $\sim 300 \mathrm{~km} / \mathrm{s}$. The two components of the distribution function are clearly

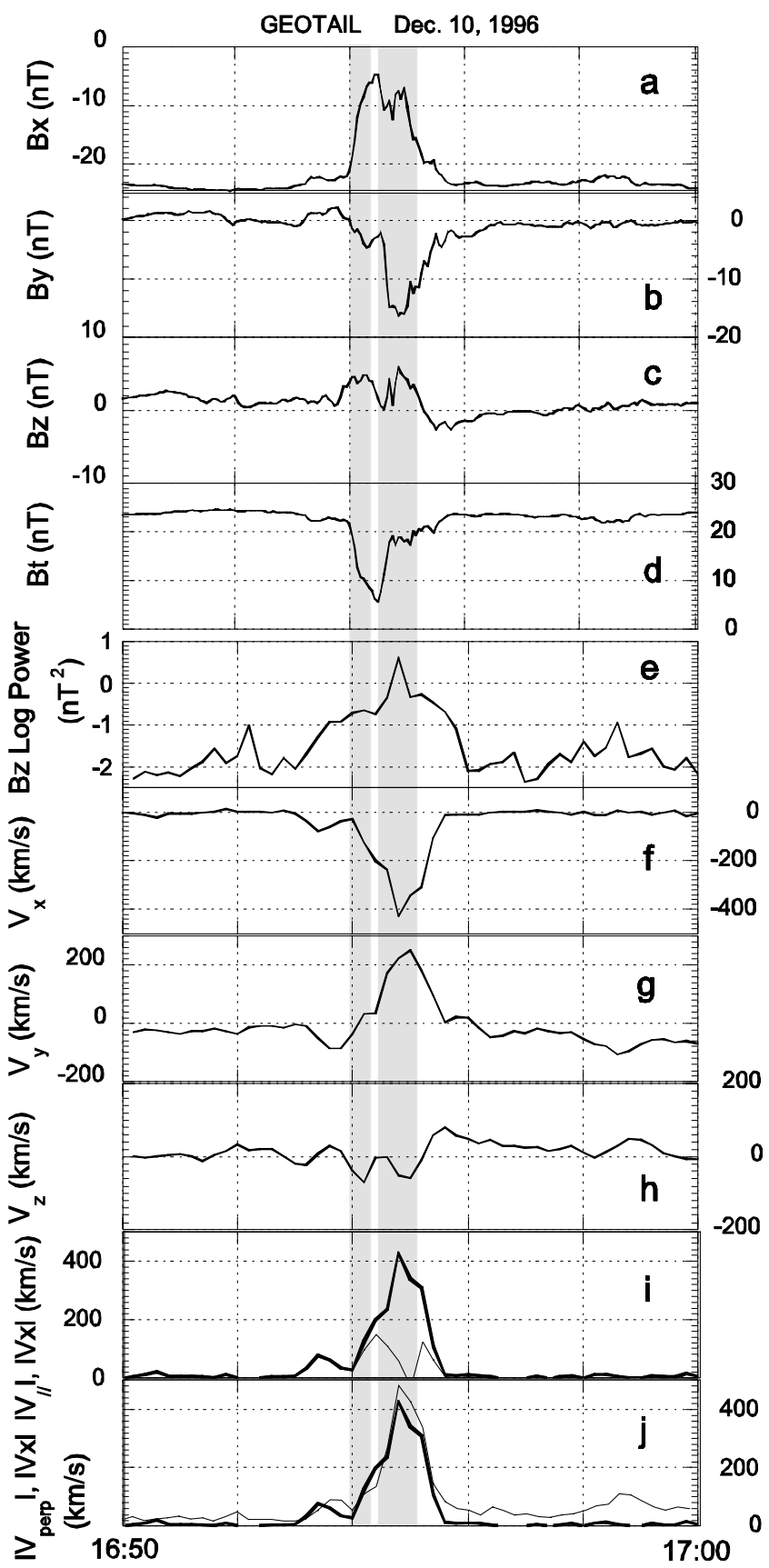

Figure 7. Geotail 3-s magnetic field, integrated power of the $B z$ component (computed over $12 \mathrm{~s}$ from the high bit rate: $16 \mathrm{~s}^{-1}$ ) and 12-s ion moments (in GSM) are shown from top to bottom for 10 December 1996. The parallel and perpendicular velocity components have been computed (thin lines). The gray areas correspond to periods of strong magnetic field variations which can alter the interpretation of the distribution functions.

separated. Hence the drift velocity can unambiguously be determined. The presence of the ion beam is also evidenced on the velocity plots by the parallel component seen in Figure 7i. The mean energy of the plasma sheet electrons is $\sim 500 \mathrm{eV}$ just before the event. When this short event occurs, heating of the electron population up to $\sim 1 \mathrm{keV}$ is 

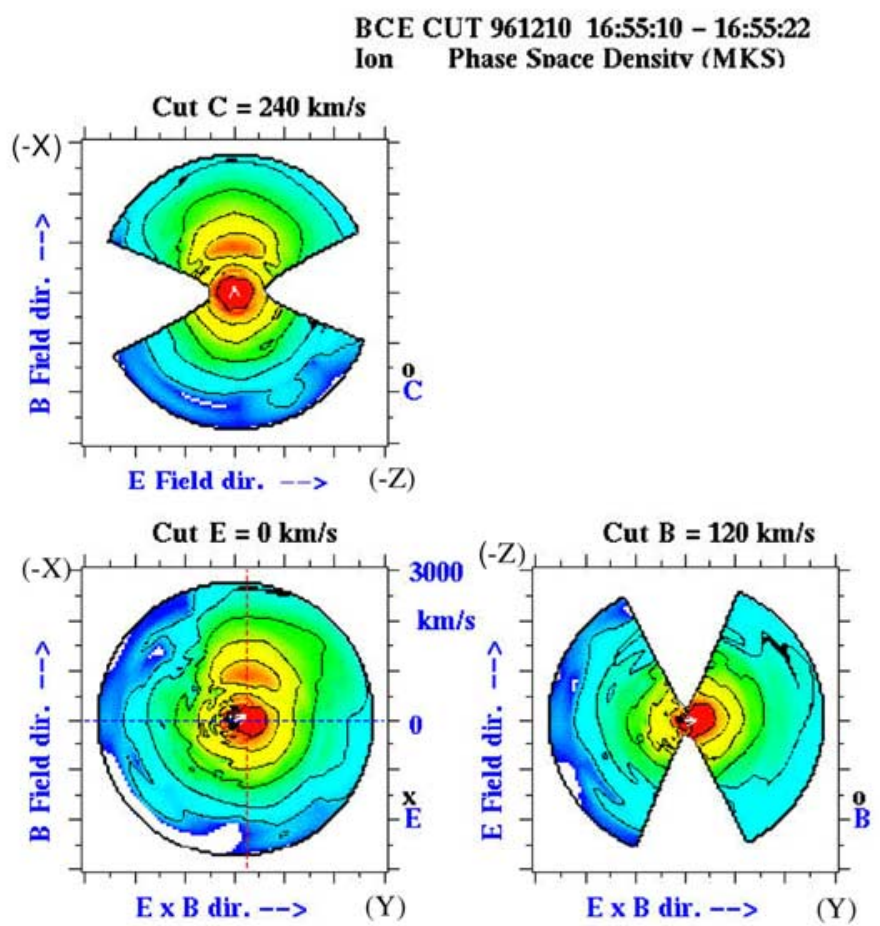
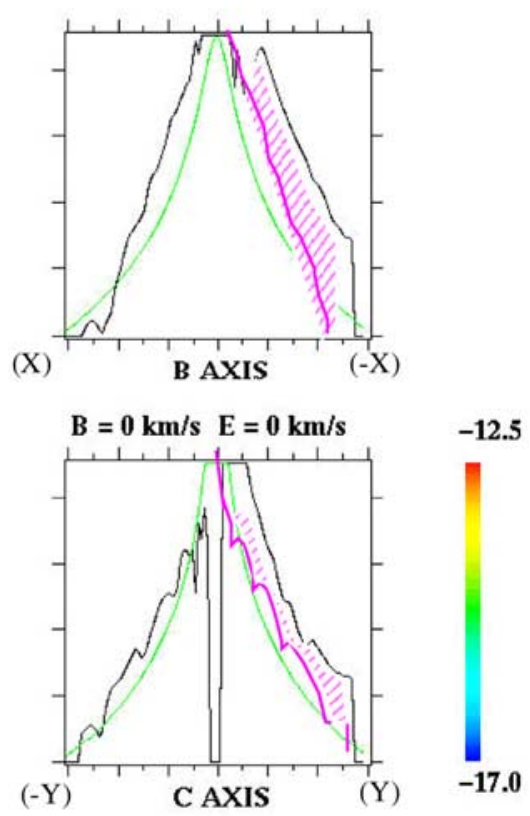

Figure 8. Distribution function for ions for a period of weak variation of the magnetic field. The distributions are plotted in three different planes with one axis along $\mathrm{B}$, the second along $\mathrm{E}$ field and the third in the $\mathrm{E} \times \mathrm{B}$ direction labeled $\mathrm{C}$. Cuts of the distribution function along the axis $\mathrm{B}$ and $\mathrm{C}$ are plotted in the right side. During this time interval, the ion distribution shows, at the same time, a strong component along $\mathrm{B}$ and the signature of a flow in the $\mathrm{E} \times \mathrm{B}$ direction.

detected together with an intensification of waves (Figure 7e). The duration of the wave intensification is short and the effect on the shape of the electron distribution function is not very strong. More spectacular is the relationship which exists between the intensity variation of the waves and the electron heating, during a long time interval during the last phase of the 10 December 1996 substorm. Figure 9 displays a spectrogram of the electron flux versus energy. The wave intensity is superimposed. We do see that the electron energy follows the wave intensity. We have displayed some of the available electron distribution functions. At 1740, before the occurrence of the flow burst, and at 1806 UT, after the flow burst, there is no wave activity and the electron distributions are Maxwellian. At 1746, large intensity waves are observed continuously during $30 \mathrm{~min}$, the electron distribution shows a strong heating, preferentially along the magnetic field (parallel temperature larger than the perpendicular ones). Given that CDAWs are observed simultaneously we suggest that this $T_{\|}>T_{\perp}$ (cigar-shaped) distribution results from the parallel heating via Landau damping. This kind of electron distribution has already been reported by Hoshino et al. [2001] as a result of reconnection processes in the plasma sheet. Ten minutes later, at 1759 UT, the electrons are still heated, but compared with the previous distribution, they have been isotropized, (possibly via pitch angle diffusion by whistler mode waves). Distribution functions for this event have also been reported by Nagai et al. [2001]. In summary, large amplitude waves coincide with strong electron heating, with in some occasion cigar shaped electron distribution functions.

\section{Summary and Conclusion}

[38] We have studied the expansion phase of a substorm occurring while the IMAGE magnetometer network was located close to midnight and the magnetic signature started at a low latitude $\left(65^{\circ}\right.$ INVL) and later regularly expanded to the north, reaching Geotail magnetic footprint $\left(\sim 70^{\circ}\right)$ a few minutes later. Simultaneously, the UV camera on Polar gave evidence for the development of a bulge. We have associated this northward expansion with a tailward expansion of the dipolarization. Geotail was located at $\sim 23 R_{E}$, in the midnight sector, close to the center of the TCS that had developed before. A large convective flow is observed when the auroral bulge hits Geotail footprint. We have taken advantage of this rare conjunction between groundbased and space-born instruments to test possible substorm models.

[39] According to the standard model [Hones, 1979], the spontaneous formation of a Near Earth Neutral Line (NENL) is what initiates substorm activity and produces fast flows, both earthward and tailward of the NENL. More recent versions of the model suggest that the braking of this fast earthward flow, on dipolar magnetic field, produces the magnetic signatures observed close to the Earth (magnetic bay and dipolarization). In the present work we do give 


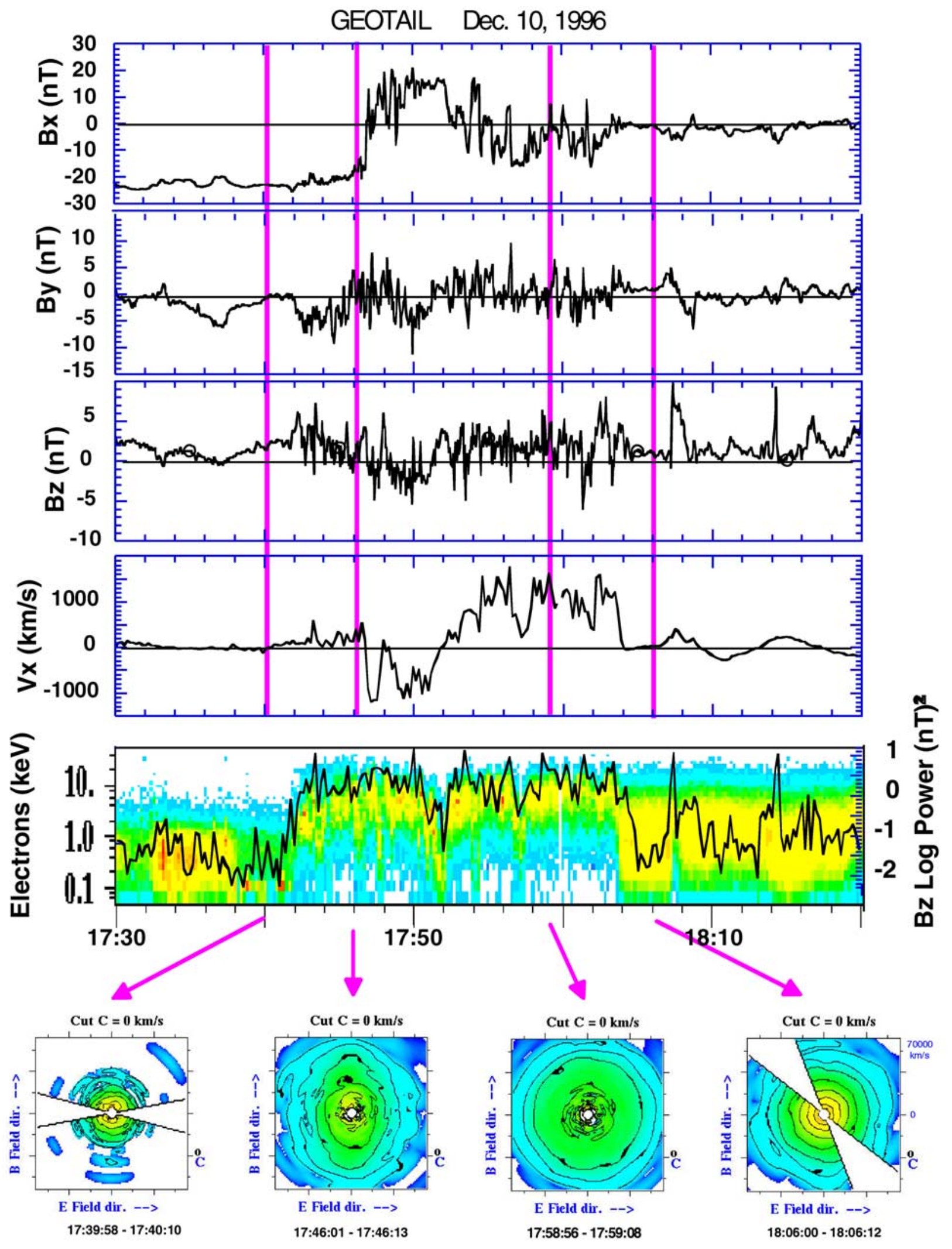

Figure 9. Geotail 3-s magnetic field (three components in GSM) and 12-s radial ion velocity are shown from top to bottom for 10 December 1996. Below, superimposed on the (energy/time) spectrogram of the electron flux, temporal variations of the wave intensity ( $B z$ component integrated over $12 \mathrm{~s}$ ). On the bottom, selection of electron distribution functions in the plane $V_{\|}, V_{\text {perp }} . V_{\text {perp }}$ corresponds to the direction of the electric field. Notice the strong relationship between the wave intensity and the electron heating. 
evidence for a tailward flow, as expected for a NENL developing earthward of Geotail $\left(\mathrm{R}<23 R_{E}\right)$. However this fast flow is observed at least 2 min after the early magnetic perturbation at low latitude. If the low-latitude auroral form and the low-latitude magnetic perturbation had been due to the spontaneous formation of an X-line between the Earth and Geotail, one would have expected to observe the tailward flow earlier than the low-latitude magnetic perturbation. In fact only when the magnetic perturbation (detected from IMAGE network) and the auroral bulge (detected from the UV images on Polar) approach the magnetic footprint of Geotail do we observe a fast tailward flow on this spacecraft. Thus present observations are not a priori consistent with a scenario where break up is due to the development of a neutral line beyond, say, $15 R_{E}$. However we cannot rule out a scenario where the neutral line develops very close to the Earth. It is also possible that a fast flow developed earlier than the ground signature but missed the spacecraft because of its narrowness in longitude. Yet, in order to be able to drive a reconfiguration of the tail a neutral line must have a wide enough extension in longitude. The corresponding flow burst (or bursts) should therefore be widely spread in longitude.

[40] Thus present observations suggest that the activity starts in the Near Earth Plasma Sheet and expands radially outward, reaching Geotail in the midtail a few minutes later. Adding the observations of INTERBALL tail located at $\sim 10 R_{E}$ in the tail at an altitude of $\sim 7 R_{E}$ below the equator, Yahnin [2000] used the same data set and concluded: "all the three main manifestations of the substorm onset (auroral breakup, current disruption, and plasmoid formation) might have the same origin time and place." Nevertheless, even after a detailed examination of other events, he "cannot make definite conclusion about what is the process launching the substorm." The observations and the mechanism we are proposing are an attempt to solve this issue. We suggest a simple model of TCS where the inner part of a TCS is progressively eroded. This erosion is associated with the disruption of the tail current, farther and farther out, as suggested by Lui [1996]. A simple current sheet model has been used to illustrate that this erosion can easily reproduce the observed magnetic signature. In this simple model, an $\mathrm{X}$-point/X-line does develop at $\mathrm{R}<23 R_{E}$ as a consequence of the current disruption, but it is forced by current disruption. Nevertheless, from this study it is difficult to assess what produces current disruption and fast flows because Geotail is too far from the triggering region.

[41] The azimuthal electric field Ey associated with the dipolarization produces an electric drift. Therefore the present interpretation is consistent with earlier findings of the Geotail team establishing a relation between the location of magnetic nulls and the flow direction. According to our interpretation, Geotail detects a tailward flow only when the retreating TCS has produced a negative $B z$ over a substantial region, between the Earth and Geotail. In agreement with this tailward motion of the dipolarization/current disruption, the auroral pattern expands to the north. During the second reactivation at the Geotail longitude (at $\sim 2110$ UT for 15 December 1996), the dipolarization region is still closer to the Earth than the Geotail position and Geotail still detects a tailward ion flow. Later, around 2123 UT, the ion velocity changes alternately from earthward/tailward/earth- ward, indicating that the current disruption region is in the vicinity of the location of Geotail. Once the current disruption occurs tailward of GEOTAIL (as indicated by Polar) the ion flow direction turns to earthward. Thus for the various phases the observations are well organized by the relative position between the spacecraft and the location of the current disruption region. In the present model, the tailward propagation of the dipolarization/current disruption front (whatever causes its erosion) can lead to the formation of an X-line/X-point. The changes in the perpendicular current $J_{y}$ produce parallel currents as the disruption propagates [Le Contel et al., 2001a; Pellat et al., 2000].

[42] The last important point obtained from the analysis of Geotail observations is relative to the waves around the proton gyrofrequency which seem to be the tracer of the flow in the tail. Whatever their direction, fast flows are always associated with intense electromagnetic fluctuations, CDAWs. Similar observations have been reported by Bauer et al. [1995]. They refer to the works of Gary et al. [1976] and Gary and Winske [1990] to identify the mode of the waves. Similar comparisons between occurrence of waves and transport of the plasma have been made at the geostationary orbit [Le Contel et al., 2001b]. These waves have been identified as Current Driven Alfvén waves, driven unstable by a parallel current [Perraut et al., 2000a]. On Geotail the magnetic signature on $B y$ and the existence of parallel flowing ions suggest that the parallel drift between ions and electrons could be the free energy source. Unfortunately, the electron flow velocity is very difficult to measure; hence evidence for parallel current is hard to obtain. According to this model electrons should preferentially be heated along magnetic field, via the CDAWs at least at high latitudes, where the Alfvén velocity increases enough to match the electron parallel velocity. We have indeed given evidence for a correlation between intense CDAWs and electron heating and in some conditions field aligned "cigar-shaped" electron distributions. The role of these waves on the reconfiguration of the magnetic field during substorms in the midtail will be studied more in details on the basis of CLUSTER data.

[43] Acknowledgments. The IMAGE magnetometer data are collected as a Finnish-German-Norwegian-Polish-Russian-Swedish project. The study has been supported by CNRS via the "Programme National Soleil-Terre."

[44] Lou-Chuang Lee thanks two reviewers for their assistance in evaluating this paper.

\section{References}

Akasofu, S. I., The development of the auroral substorm, Planet. Space Sci., 12, 273, 1964.

Angelopoulos, V., R. C. Elphic, S. P. Gary, and C. Y. Huang, Electromagnetic instabilities in the plasma sheet boundary layer, J. Geophys. Res., 94, 15,373, 1989

Angelopoulos, V., C. F. Kennel, F. V. Coroniti, R. Pellat, M. G. Kivelson, R. J. Walker, C. T. Russell, W. Baumjohann, C. W. Feldmann, and J. T. Gosling, Statistical characteristics of bursty bulk flow events, J. Geophys. Res., 99, 21,257, 1994

Bauer, T. M., W. Baumjohann, R. A. Treumann, N. Sckopke, and H. Lühr, Low-frequency waves in the near-Earth plasma sheet, J. Geophys. Res., 100, 9605, 1995.

Baumjohann, W., R. J. Pellinen, H. J. Opgenoorth, and E. Nielsen, Joint two-dimensional observations of ground magnetic and ionospheric electric fields associated with auroral zone currents: Current systems associated with local auroral break-ups, Planet. Space Sci., 29, 431, 1981.

Baumjohann, W., G. Paschmann, and H. Lühr, Characteristics of highspeed ion flow in the plasma sheet, J. Geophys. Res., 95, 3801, 1990. 
Elphingstone, R. D., et al., The double oval UV auroral distribution: 1. Implications for the mapping of auroral arcs, J. Geophys. Res., 100, $12,075,1995$.

Frank, L. A., J. B. Sigwarth, W. R. Paterson, and S. Kokubun, Two encounters of the substorm onset region with the Geotail spacecraft, J. Geophys. Res., 106, 5811, 2001a.

Frank, L. A., W. R. Paterson, J. B. Sigwarth, and T. Mukai, Observations of plasma sheet dynamics earthward of the onset region with the Geotail spacecraft, J. Geophys. Res., 106, 18,823, $2001 \mathrm{~b}$.

Gary, S. P., and D. Winske, Computer simulations of electromagnetic instabilities in the plasma sheet boundary layer, J. Geophys. Res., 95, 8085, 1990 .

Gary, S. P., R. A. Gerwin, and D. W. Forslund, Electromagnetic current instabilities, Phys. Fluids., 19, 579, 1976.

Håland, S., et al., Magnetospheric and ionospheric response to a substorm: Geotail and Polar PXIE observations, J. Geophys. Res., 104, 28,459, 1999.

Hones, E. W., Jr., Plasma flow in the magnetotail and its implications for substorm theories, in Dynamics of the Magnetosphere, edited by S.-I. Akasofu, pp. 545, D. Reidel, Norwell, Mass., 1979.

Hoshino, M., A. Nishida, T. Yamamoto, and S. Kokubun, Turbulent magnetic field in the distant magnetotail: Bottom-up process of plasmoid formation?, Geophys. Res. Lett., 21, 2935, 1994.

Hoshino, M., K. Hiraide, and T. Mukai, Strong electron heating and NonMawvellian behavior in magnetic reconnection, Earth Planets Space, 53, 627, 2001.

Jacquey, C., J. A. Sauvaud, and J. Dandouras, Location and propagation of the magnetotail current disruption during substorm expansion: Analysis and simulation of an ISEE multi-onset event, Geophys. Res. Lett., 18, 389, 1991.

Le Contel, O., R. Pellat, and A. Roux, Self-consistent quasi-static radial transport during the substorm growth phase, J. Geophys. Res., 105, $12,929,2000$.

Le Contel, O., S. Perraut, A. Roux, and R. Pellat, Plasma transport during substorm growth phase and relation to breakup, Space Sci. Rev., 95, 415, 2001a.

Le Contel, O., A. Roux, S. Perraut, R. Pellat, Ø. Holter, A. Pedersen, and A. Korth, Possible control of the plasma transport in the near-Earth plasma sheet via current driven Alfvén waves $(\mathrm{f} \sim \mathrm{fH}+)$, J. Geophys. Res., 106, $10,817,2001 b$.

Liou, K., et al., Synoptic auroral distributions: A survey using Polar ultraviolet imagery, J. Geophys. Res., 102, 27,197, 1997.

Lui, A. T. Y., Current disruption in the Earth's magnetosphere: Observations and models, J. Geophys. Res., 101, 13,067, 1996.

Nagai, T., M. Fujimoto, Y. Saito, S. Machida, T. Terasawa, R. Nakamura, T. Yamamoto, T. Mukai, A. Nishida, and S. Kokubun, Structure and dynamics of magnetic reconnection for substorm onsets with Geotail observations, J. Geophys. Res., 103, 4419, 1998a.

Nagai, T., R. Nakamura, S. Kokubun, T. Yamamoto, and T. Mukai, Plasma sheet dynamics during substorms with Geotail observations, in $S U B$ STORMS-4, edited by S. Kokubun and Y. Kamide, p. 137, Terra Sci., Tokyo, 1998b.

Nagai, T., I. Shinohara, M. Fujimoto, M. Hoshino, Y. Saito, S. Machida, and T. Mukai, Geotail observations of the Hall current system: Evidence of magnetic reconnection in the magnetotail, J. Geophys. Res., 106, $25,929,2001$

Nakamura, R., S. Kokubun, T. Mukai, Y. Yamamoto, M. Brittnacher, and G. Parks, Temporala and spatial relationships between midtail substorm disturbance and auroral substorm onset, in SUBSTORMS-4, edited by S. Kokubun and Y. Kamide, p. 179, Terra Sci., Tokyo, 1998.

Ohtani, S., S. Kokubun, and C. T. Russell, Radial expansion of the tail current disruption during substorms: A new approach to the substorm onset region, J. Geophys. Res., 97, 3129, 1992.
Parks, G. K., L. J. Chen, M. Fillingim, and M. McCarthy, Kinetic characterization of plasma sheet dynamics, Space Science Rev., 95, 237, 2001.

Paterson, W. R., L. A. Frank, S. Kokubun, and T. Yamamoto, Geotail survey of ion flow in the plasma sheet: Observations between 10 and 50 RE, J. Geophys. Res., 103, 11,811, 1998.

Paterson, W. R., L. A. Frank, S. Kokubun, and Y. Yamamoto, Reply, J. Geophys. Res, 104, 17,527, 1999.

Pellat, R., O. Le Contel, A. Roux, S. Perraut, O. H. Hurricane, F. V. Coroniti, and J. F. Luciani, Une nouvelle approche pour les sous-orages magnétosphériques, C.R. Acad. Sci. Paris, 1, 975, 2000.

Perraut, S., A. Morane, A. Roux, A. Pedersen, R. Schmidt, A. Korth, G. Kremser, B. Aparicio, and R. Pellinen, Characterization of small scale turbulence observed at substorm onsets: Relationships with parallel acceleration of particles, Adv. Space Res., 13, 217, 1993.

Perraut, S., A. Roux, F. Darrouzet, C. de Villedary, M. Mogilevsky, and F. Lefeuvre, ULF waves measurements on board the INTERBALL Auroral probe, Ann. Geophys., 16, 1105, 1998.

Perraut, S., O. Le Contel, A. Roux, and A. Pedersen, Current driven electromagnetic ion cyclotron instability at substorm onset, J. Geophys. Res., 105, 21,097, 2000a.

Perraut, S., O. Le Contel, A. Roux, A. Ø. Korth, O. Holter, and A. Pedersen, Disruption of parallel current at substorm breakup, Geophys. Res. Lett., 27, 4041, 2000b.

Roederer, J. G., Dynamics of Geomagnetically Trapped Radiation, p. 102, Springer-Verlag, New York, 1970.

Schödel, R., W. Baumjohann, R. Nakamura, V. A. Sergeev, and T. Mukai, Rapid flux transport in the central plasma sheet, J. Geophys. Res., 106, 301, 2001

Shinohara, I., T. Nagai, M. Fujimoto, T. Terasawa, T. Mukai, K. Tsuruda, and Y. Yamamoto, Low-frequency electromagnetic turbulence observed near the substorm onset site, J. Geophys. Res., 103, 20,365, 1998.

Shiokawa, K., W. Baumjohann, and G. Haerendel, Braking of high speed flows in the near-Earth tail, Geophys. Res. Lett., 24, 1179, 1997.

Sigsbee, K., C. A. Cattell, F. S. Mozer, K. Tsuruda, and S. Kokubun, Geotail observations of low-frequency waves from 0.001 to $16 \mathrm{~Hz}$ during the November 24, 1996, Geospace environment modelling substorm challenge event, J. Geophys. Res., 106, 435, 2001.

Tsyganenko, N. A., A magnetospheric magnetic field model with a warped tail current sheet, Planet. Space Sci., 37, 5, 1989.

Tu, J.-N., K. Tsuruda, H. Hayakawa, A. Matsuoka, T. Mukai, I. Naganao, and S. Yagitani, Statistical nature of impulsive electric fields associated with fast ion flow in the near-Earth plasma sheet, J. Geophys. Res., 105, $18,901,2000$.

Yahnin, A. G., Observational constraints on the plasma sheet processes related to auroral breakup, paper presented at 5th International Conference on Substorms, St. Petersburg, Russia, 16-20 May 2000.

D. Chua and G. Parks, Department of Earth and Space Sciences, University of Washington, Box 351310, Seattle, WA 98195-1310, USA. (damien@geophys.washington.edu; parks@ssl.berkeley.edu)

M. Hoshino, University of Tokyo, Tokyo 113, Japan. (hoshino@eps.s. u-tokyo.ac.jp)

O. Le Contel, S. Perraut, and A. Roux, CETP/CNRS/UVSQ, 10-12 Av. de l'Europe, 78140-Vélizy, France. (Olivier.LeContel@cetp.ipsl.fr; sylvaine. perraut@cetp.ipsl.fr; Alain.Roux@cetp.ipsl.fr)

T. Mukai, Institute of Space and Aeronautical Science, Sagamihara, Kanagawa 229-8510, Japan. (mukai@stp.isas.ac.jp)

T. Nagai, Tokyo Institute of Technology, Tokyo 152-8551, Japan. (nagai@geo.titech.ac.jp) 